\title{
A REVIEW OF DIGITAL TWIN APPLICATIONS IN CONSTRUCTION
}

SUBMITTED: July 2021

REVISED: December 2021

PUBLISHED: February 2022

EDITOR: Robert Amor

DOI: $10.36680 / j$. itcon.2022.008

\author{
Obinna C. Madubuike, Doctoral Candidate, \\ M.E. Rinker Sr. School of Construction Management, University of Florida \\ omadubuike@ufl.edu
}

Chimay J. Anumba, Professor and Dean, College of Design, Construction, and Planning, University of Florida anumba@ufl.edu

Rana Khallaf, Assistant Professor, Structural Engineering and Construction Management Department, Future University in Egypt, Cairo, Egypt rana.khallaf@fue.edu.eg

SUMMARY: The emergence of digital twin technology presents tremendous opportunities for several industry sectors. A digital twin is defined as the virtual representation of a physical asset that collects and sends real-time information. A digital twin collects data from the physical asset in real-time and uses this data to create a virtual model of the physical object. Its functionality depends on the bi-directional coordination of data between the physical and virtual models. This is likened to cyber-physical systems, which seek to provide bi-directional coordination between the physical and virtual worlds. While digital twins have found applications in the various industrial sectors such as aerospace, manufacturing, and industrial engineering, their applications in the construction industry are relatively limited. Although some level of progress has been made in the construction industry with the application of a digital twin, it still lags in other sectors. Virtual models of constructed facilities are developed and used to plan and construct the actual facility, with changes in the physical facility being automatically reflected in the virtual model based on real-time data and vice-versa. The digital twin shows promising possibilities in the design, construction, operation, and maintenance of a facility. This paper reviews the development and implementation of digital twin technology in the construction industry and compares its use with other industries while assessing the benefits of DT to the construction industry. A systematic literature review including a thematic analysis was employed to address the purpose of this study. Limitations associated with the existing and emerging applications are also identified. It concludes by highlighting the importance of DT applications in the construction sector.

KEYWORDS: Bi-directional, Data Analytics, Digital Twin, Cyber-Physical Systems, Virtual Model, Real-Time.

REFERENCE: Obinna C. Madubuike, Chimay J. Anumba, Rana Khallaf (2022). A review of digital twin applications in construction. Journal of Information Technology in Construction (ITcon), Vol. 27, pg. 145-172, DOI: 10.36680/j.itcon.2022.008

COPYRIGHT: () 2022 The author(s). This is an open access article distributed under the terms of the Creative Commons Attribution 4.0 International (https://creativecommons.org/licenses/by/4.0/), which permits unrestricted use, distribution, and reproduction in any medium, provided the original work is properly cited. 


\section{INTRODUCTION}

Technology is a dynamic concept that improves with time-based on the accumulated information in an environment. It is continually developing with the aid of bits and atoms, which has led to the harmonization of work and play such that much is achieved with little effort (Negroponte, 1995). Advancements in virtual modeling and data acquisition technology have enabled the development of the concept of digital twins. Digital Twin (DT) technology involves the development of a living digital model of the physical asset, which has the characteristics of continually adapting to changes in the physical environment or operations and delivering the best result (Parris et al, 2016). The DT can improve based on its adaptations to the environment, which is achieved through the effective simulation of data obtained using embedded sensors. A DT is created by first developing a virtual model of the physical object by using and analyzing the physical object's data and having a synchronized link with the physical object, which allows for easy monitoring (GAVS, 2017).

DT provides the possibility of monitoring and controlling the state of the physical objects through the virtual model. It has the capability of improving the efficiency and lifespan and reducing the operational cost of a physical entity by providing a platform that enables a proactive and predictive maintenance cycle (Liu et al, 2018). DT uses tools and technologies to map the stored data of the physical object (Palit \& Datta, 2017), which helps to produce up-to-date information on the physical object. It operates based on the synchronized real-time information coordination between the hardware (physical object) and software (virtual object) as in cyber-physical systems. DT is yet at the nascent stage but has shown diverse applicability in the various industrial sectors. This study reviews the applications of DT in various sectors, including the construction sector. Unfortunately, the construction industry is yet to fully embrace the implementation of DT, which can be attributed to the complex nature of the industry and the slow receptiveness of the stakeholders. Additionally, publications on DT application in the construction industry have been observed to be very low. This could be attributed to the low implementation of DT in the construction industry.

Previous literature has shown a huge gap in the implementation of DT between the industrial sectors and the construction industry. Hence, the purpose of this paper is to systematically review DT applications, identify the various themes of some of the literature employed by this study using thematic analysis approach, investigate the extent of DT implementation in the construction industry, and identify recommendations from the other industries where DT has been successfully implemented. This study starts with an introduction to DT and an identification of its key features. It highlights the systematic method and thematic analysis used to analyze the literature reviewed for this study. It goes further to describe DT applications in several industries. This is followed by a review of DT applications in the construction industry. Finally, the importance and benefits of DT applications in the construction industry are outlined in the concluding part of the paper.

\section{DIGITAL TWINS - KEY CONCEPTS}

\subsection{History}

Within the context of DT, the earliest mention of a 'twin' is in the field of aerospace and can be traced back to NASA Technology Roadmaps - NASA's Apollo project in the 1960s (Shafto et al. 2010; Negri et al. 2017; Boschert et al, 2018). The NASA project entailed the creation of two space vehicles with one on earth as 'the twin' that mirrored the space vehicle performing the mission (Boschert et al, 2018; Zhuang et al, 2018). Rosen et al. (2015) identified the twin as a prototype that reflected the operations of the space vehicle in real-time. However, the 'twin' was a physical system during this period (Zhuang et al, 2018). The digital aspect was not at this time included in the title 'twin'. Consequently, the term 'Digital Twin' was first mentioned by Michael Grieves in 2003 when he introduced the concept in his course on product lifecycle management (PLM) (Grieves, 2014). PLM combines various business activities that deal with the creation, modification, and use of data to support all product lifecycle phases from design and production through use and maintenance to recycling and disposal (Schroeder et al, 2016). Kritzinger et al. (2018) explained more on PLM, which referred to an industry presentation describing DT as a digital informational construct of a physical system created as an entity on its own but linked to the physical system. Subsequent definitions and applications of DT have followed this line of thought for creating a digital model linked to the physical entity with the aid of smart devices and updating the digital model in real-time using a viable communication network. To ensure that the DT optimally represents the physical system, Grieves and Vickers (2017) state that the DT must include all information about the physical system asset obtained through 
diligent inspection of the real world. Figure 1 shows a summary of the milestone progress made in the development of the DT concept.

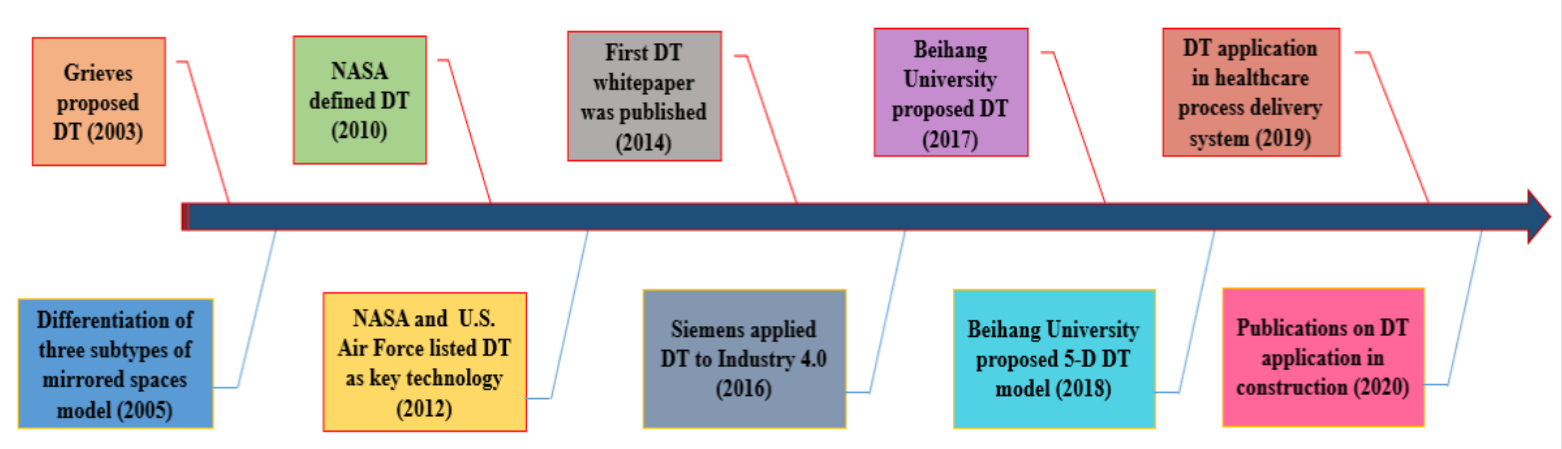

FIG 1: The milestone of DT development (Adapted from Qi et al, 2019).

\subsection{Definition of Digital Twin}

The first step in understanding the concept of DT is through a well-articulated definition. Various definitions have been coined by different authors to explain what DT technologies mean. Michael Grieves coined the first DT definition as an information mirroring model in his product lifecycle management course (Grieves, 2005). Although, this definition does not provide a detailed concept of DT. Subsequent DT definitions have been developed by several authors. Rosen et al. (2015) defined DT as a combination of both physical and virtual spaces which mirror each other to evaluate the lifecycle operations of the physical component. This definition briefly explains the purpose of the DT and the components involved. Shortly thereafter, a more concise definition was coined by Boschert and Rosen (2016) that DT encompasses all the physical and functional data useful from a product or system. This definition focused more on the data exchange and algorithms that control the behavior of the physical and virtual models. Although concise, this definition focused only on the DT data, neglecting its components and purpose. Grieves and Vickers (2017) further defined DT in the context of product lifecycle management as a set of virtual information constructs that provide a true representation of a potential or actual physical manufactured product from its atomic level to the macro geometrical level. It is the virtual representation of what has been manufactured. The intention was to compare a DT to its engineering design (physical object) to better understand the quality of the end-product to the digital design, thereby, narrowing loopholes between design and execution (Grieves and Vickers, 2017). Compared to the earliest definition of Grieve (2005), this definition provides an elaborate detail on DT but focuses more on product lifecycle management.

Lui et al. (2018) further defined DT as a living model which represents a physical asset or system that continually adapts to changes in operations based on online data and information collected and can predict the future of the corresponding physical counterpart. This definition is more elaborate compared to the previous DT definitions. Essentially, a DT uses tools, technologies, and a communication system (internet) to collect data from physical objects to simulate their virtual models. Madni et al (2019) defined DT, not as a virtual prototype but rather a virtual instance of a physical system's (twin) performance, maintenance, and health status data, which is continually updated throughout the life cycle of the physical system. The definitions by Lui et al (2018) and Madni et al. (2019) focused on the ability of DT to improve over time based on the level of information update collected from the physical asset and used to monitor the performance of the physical asset. These definitions are most inclusive and appropriate for the construction sector because they address the purpose of DT in this industry real-time monitoring of construction projects and predictive maintenance. Furthermore, a DT shows the live update of the status of the physical object and provides predictable models based on the amount of accumulated information.

Following the previous DT definitions, this study defines DT as the virtual representation of a physical asset using the DT-enabling technologies such as sensors, communication networks, and 3D models to obtain real-time updates and effect bi-directional coordination such that the virtual model represents a replica of the physical asset. This definition identified DT by identifying the enabling technologies, DT features, and purpose. Following the DT definitions, DT has several possibilities of being applied in different fields to meet the purpose of creation. 


\subsection{Key Features}

The emergence of DT has created new platforms and paths to enable functionalities and services to be carried out in the easiest of ways. DT has been identified as one of the most promising state-of-the-art digital platforms which creates digital/virtual twins of physical assets (Martinez et al., 2018). DT functions are based on the principle of the interaction between the physical and virtual worlds, which enables the analysis of data and monitoring of systems (GAVS, 2017). The interaction between the physical entity and virtual model is fostered by highly effective communication platforms using real-time updates. The Internet of Things (IoT) has been identified as a viable communication platform that functions on the combination of sensors, cloud computing, and big data analytics (Lui et al, 2018). The data and information transmitted between both ends are the brain box behind the functionality of DT. It enables continuous information flow between a physical and virtual asset throughout the product lifecycle of the asset (Abramovici et al, 2015; Rosen, 2016). This enables a DT to imitate a physical asset by continuously adapting to operational changes based on the information and online data collection and in turn providing future predictions as it affects the physical asset. This causes maintenance strategies to move from being reactive to predictive by forecasting what maintenance measures would be needed by the physical asset.

DT involves a systems-of-systems integration of the different sources of data that include embedded sensors, wireless sensor networks, digitized building life-cycle data and systems, and integration with other cloud services and data providers (Haag \& Anderl, 2018). The data are collected based on real-time information, which provides a DT with the characteristics of continually adapting to changes in the environment or operations and delivering the best outcomes. This is easily achieved using sensors to properly synchronize the DT to the physical asset with the aid of the internet. The sensors receive data in real-time and continually update the virtual model (Lui et al, 2018). Consequently, DT consists of three parts, which include the physical product, virtual product, and the communication platform between them (Glaessgen \& Stargel 2012). An essential part of a DT is the communication (linkage) between the physical and virtual products, which involves analytics at every step. Madni et al. (2019) identified several features of DT to include:

- A DT reflects the specific instance of a physical structure, its performance, maintenance, repair history, health status, and other characteristics.

- It uses historical data of the physical structure to determine schedules for preventive maintenance.

- It uses the virtual model to monitor and understand the performance of the physical asset and predict future performance and maintenance patterns.

- Developers/facility managers can monitor the performance of the system and make possible adjustments to meet expected requirements.

- There are possibilities of tracing life cycle phases of physical assets through the provided connectivity by the digital threads.

- Future system performance can be predicted following the refinement of assumptions using predictive analytics data obtained from the physical structure.

- There is a possibility of performing remote maintenance by troubleshooting malfunctioning remote equipment.

- It optimizes and improves services and operations by combining data from the IoT with data from the physical asset.

- A DT can simulate operational and maintenance data of the physical system to reflect the age of the physical system.

\subsection{Steps to Implementing Digital Twin Technology}

DT is based on the foundation of the Internet of Things (IoT) for its operations (Palit \& Datta, 2017). Its implementation depends on the level of information needed to create and continuously feed the model (Deloitte, 2017), and the level of IoT employed. The purpose of the DT application determines the amount of information (Level of Detail - LoD) uploaded in the virtual model. To implement DT technology, a process is needed to identify the appropriate level of detail and complexity. The following is a six-step process for implementing DT technology (Deloitte, 2017): (a) imagination of opportunities: the possible opportunities are imagined and assessed at this stage based on the pre-defined characteristics to identify suitable scenario; (b) identification of a suitable process: identifying the DT configuration with the highest possible value and best chance of being successful based on factors such as operational, business, and organizational change management; (c) pilot the DT: a pilot program in repetitive and agile cycles are carried out to accelerate learning, proactively manage risk, and ensure return on 
initial investment is maximized; (d) industrialize the process: the piloted DT scenario is industrialized using established tools, techniques, and playbooks to ensure that the developed scenario is applicable in the fields required; (e) scale the twin: values obtained during the piloting together with tools, techniques, and playbooks are communicated with the larger enterprise and stakeholders to ensure improvement and that developed DT scenario meets the needs of the enterprise; and (f) monitor and measure: to ensure that the results obtained are of optimum value, the solutions arrived at are monitored to accurately measure the values obtained from the DT.

\subsection{System Architecture}

To address the system architecture, an adequate understanding of the dynamics required in the functionality of DT is essential. These dynamics, which also define the system architecture of DT, depend on CAD and other related engineering information such as product specifications, geometry models, material properties, validation results, IoT sensor readings, and associated simulation information (Padmanabhan, 2018). The intended use of the DT determines what model needs to be used to create it. If properly implemented, it will influence how the design, build, and operation of the physical system is constructed and works in a single life cycle. DT involves three major parts which include the physical system, virtual system, and the communication linkage between both systems (Glaessgen \& Stargel 2012). These parts are comprised of DT-enabling technologies including cyber-physical systems, sensors, communication networks, and mobile devices. The cyber-physical systems ensure seamless integration between the virtual and physical models (Akanmu et al, 2012; Akanmu et al, 2013; Akanmu and Anumba, 2015). The sensors are attached to the physical system to obtain relevant data needed for simulation with the virtual model to describe the behavior of the physical object and provide relevant solutions where needed (Boschert et al, 2018). The generated information by the attached sensors is updated in the cloud through the IoT and this information is updated along with the virtual system to provide the most recent information about the physical system.

DT takes advantage of the benefits of IoT to enable information flow from raw sensory data to high-level knowledge (Lui et al., 2018). This process requires some knowledge in simulation, artificial intelligence (AI), and machine learning (ML). The processing of the data and information obtained by the various attached sensors is responsible for all real-time updates in the virtual model. The data mining and processing phase is termed the interaction and convergence characteristics of the DT (Tao et al, 2018). These characteristics of the DT entail data mining from the physical system and synchronizing both the historical and real-time data to ensure a smooth connection channel between both spaces (Tao et al, 2018).

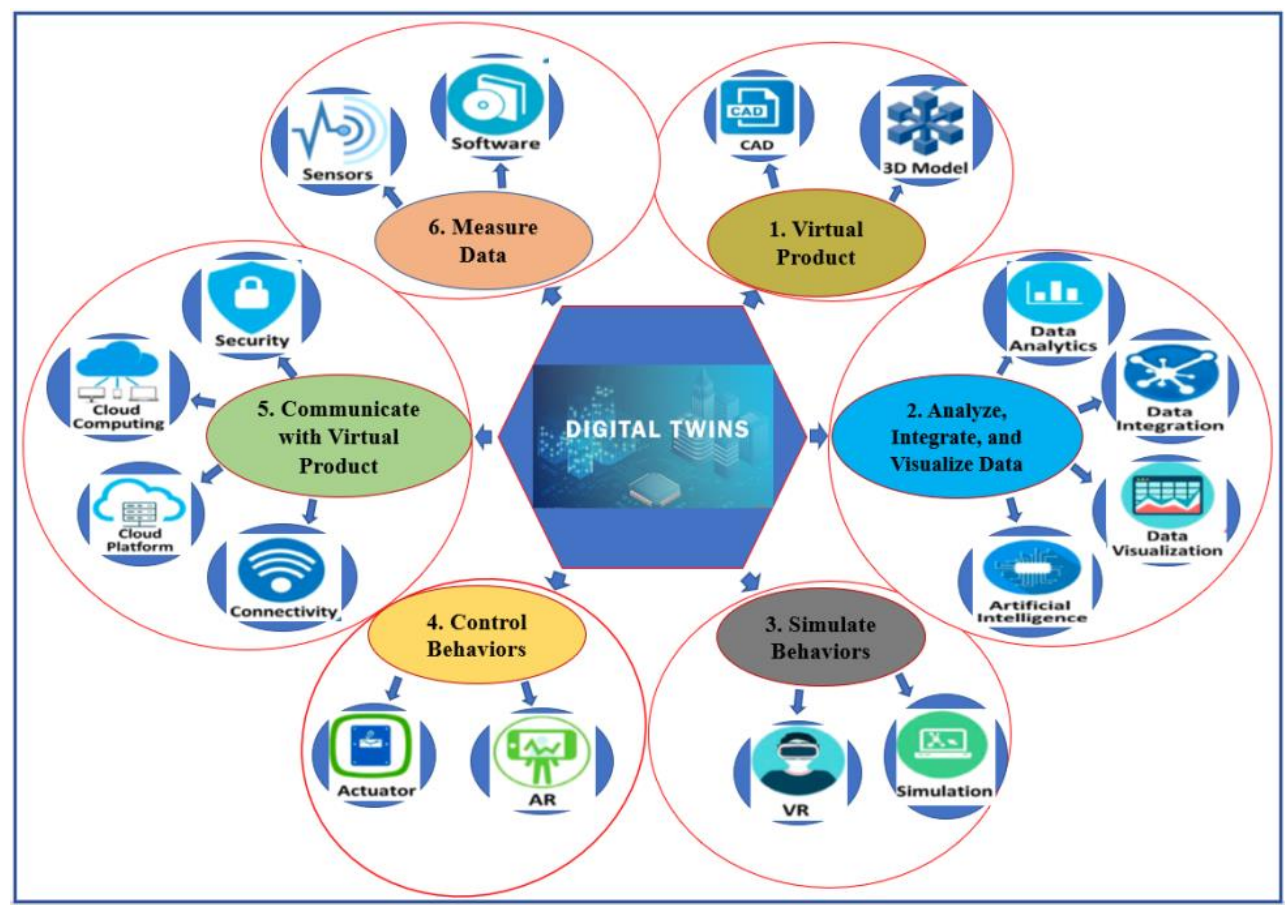

FIG 2: DT Enabling Technologies (Adapted from Tao et al, 2018). 
In a summarized context, Castaldini (2019) identified the four key components of a DT to include data (such as building systems, external data, and blueprint data), reasoning (such as AI/ML models or non-linear rules), key performance indicators (such as efficiency, emissions, net operating income and safety indicators), and context (such as occupant behavior, system/device behavior and workflows). These four key components define the system architecture and functionality of a DT. Tao et al., (2018) further broke down these four key components into six: virtual product, analysis, integration, and visualization of data, behavior simulation, behavior control, communication with the virtual product, and data measurement. These key components encompass the enabling technologies of DT. The DT enabling technologies are relevant in designing any DT system architecture. Figure 2 shows the enabling technologies of DT, highlighting the six parts as identified by Tao et al. (2018).

\section{METHODOLOGY}

The following main research and sub-research questions are presented to address the research gaps identified by this study. The main research question includes:

RQ: What is the extent of DT application in the construction industry and what prospects are there?

To properly address the main research question, the following sub-research questions are posed:

RQ1: What themes exist to identify DT publications in the various industrial sectors or fields?

RQ2: What percentage of DT publications are related to the construction industry?

RQ3: How has DT been applied in other industry sectors and what lessons are there for the construction industry?

To address the following research questions, this study employed a detailed literature review, which involved a systematic selection and analysis of relevant literature to investigate the extent to which DT was implemented in the other industries while drawing more focus on the construction industry. The systematic literature review adopted a 'Thematic Analysis approach to analyze the literature used for this study. Thematic Analysis is a type of qualitative analysis used to classify and present themes dealing with different subjects (Boyatzis, 1998; Alhojailan, 2012). The Thematic Analysis approach was adopted to identify and compare different kinds of literature on digital twin by identifying their themes with regards to the field or industry their address. This is to better understand the level of DT application and DT literature publication while comparing the various identified industries and fields. The Thematic Analysis was subjected to further analysis to identify the mean and percentage values of DT publications based on their themes.

In undertaking the literature review, relevant articles were sourced from Web of Science (managed by Clarivate Analytics) and Google Scholar (managed by Google). These two literature databases were combined to search for articles extensively because the concept proposed by this study is still gaining ground and as such, one single database could not provide all relevant and needed articles. While searching for DT articles in Scopus using Title (TI), it gave a '0' result which means that there are no DT articles in Scopus. On Web of Science, the first basic search with "digital twin" as the search input using "topic" retrieved 1,557 results between 1900 - 2020, including irrelevant articles which only mentioned the search input but had no basic support literature on it. The date range was to ensure that no publication on DT applications was ignored. A second advanced search was carried out using the input $($ Title $=\mathrm{TI})$ : TI = "digital twin" with all other settings remaining the same, this retrieved 413 results in which the term digital twin was mentioned. A third advanced search using input TI = "digital twin" was repeated and still retrieved a total of 413 results where the term digital twin was mentioned. Further advanced searches (fourth and fifth) were done using search inputs TI = "digital twin(s)" and TI = "Digital" which still retrieved the same results of 413. To ensure that more relevant literature was obtained for this study, a final search using the input: TI = "Digital Twin and Construction" was repeated as this is the core focus of this study. The results obtained for this final search are as shown in Tables 1 and 2. The followings are the summary of the search inputs used in the search for DT related topics in Web of Science:

1. Topic $=$ ("digital twin")

2. $\mathrm{TI}=$ ("digital twin")

3. $\mathrm{TI}=$ ("digital twin")

4. $\mathrm{TI}=$ ("digital twins")

5. $\mathrm{TI}=$ ("Digital")

6. $\quad \mathrm{TI}=$ ("Digital Twin and Construction") 
Table 1: Result summary of TI = "Digital Twin and Construction" publications in years.

\begin{tabular}{lll}
\hline Year & Frequency & Percentage \\
\hline 2021 & 17 & 70.83 \\
2020 & 5 & 20.83 \\
2019 & 2 & 8.33 \\
\hline Total & 24 & 100.00 \\
\hline
\end{tabular}

According to Table 1, it can be observed that publications on "Digital Twin and Construction" have been low between 2019 and 2020. However, the publications increased in 2021 to reach $70.83 \%$ of the total between 2019 and 2021. This is still low when compared to other industrial sectors like the manufacturing industry, which has benefited more from the implementation of DT. Furthermore, Web of Science categorized these publications into various applicable fields based on their contents. Table 2 shows the results of the categorization.

Table 2: Web of Science categories on TI = "Digital Twin and Construction" publications.

\begin{tabular}{lll}
\hline Categories & Frequency & Percentage \\
\hline Engineering Manufacturing & 7 & 11.67 \\
Engineering Civil & 6 & 10.00 \\
Construction Building Technology & 5 & 8.33 \\
Computer Science Interdisciplinary Applications & 4 & 6.67 \\
Engineering Multidisciplinary & 4 & 6.67 \\
Chemistry Multidisciplinary & 3 & 5.00 \\
Computer Science Information Systems & 3 & 5.00 \\
Materials Science Multidisciplinary & 3 & 5.00 \\
Physics Applied & 3 & 5.00 \\
Automation Control Systems & 2 & 3.33 \\
Engineering Electrical Electronic & 2 & 3.33 \\
Engineering Industrial & 2 & 3.33 \\
Operations Research Management Science & 2 & 3.33 \\
Robotics & 2 & 3.33 \\
Telecommunication & 2 & 3.33 \\
Architecture & 1 & 1.67 \\
Computer Science Artificial Intelligence & 1 & 1.67 \\
Environmental Sciences & 1 & 1.67 \\
Environmental Studies & 1 & 1.67 \\
Geography Physical & 1 & 1.67 \\
Green Sustainable Science Technology & 1 & 1.67 \\
Management & 1 & 1.67 \\
Remote Sensing & 1 & 1.67 \\
Transportation Science Technology & 1 & 1.67 \\
Water Resources & 60 & 1.67 \\
\hline Total & 3 & 100.00 \\
\hline
\end{tabular}

Although the search input "TI" was for "Digital Twin and Construction", several of the publications under this heading were more about "Engineering Manufacturing" and "Engineering Civil", followed by "Construction Building Technology as shown under the 'Theme' in Table 3. The categorization of the publications by Web of Science deals with identifying the various fields a publication is affiliated with based on its contents.

Based on the review of the abstracts, the relevant articles were selected for the full study. Table 3 shows a summary of some of the reviewed articles. Following the reviewed articles, more focus was on the manufacturing industry, healthcare sector, and articles on the general DT concept. This also supports the stance on the lack of adequate publications and implementation of DT technology in the construction industry. 


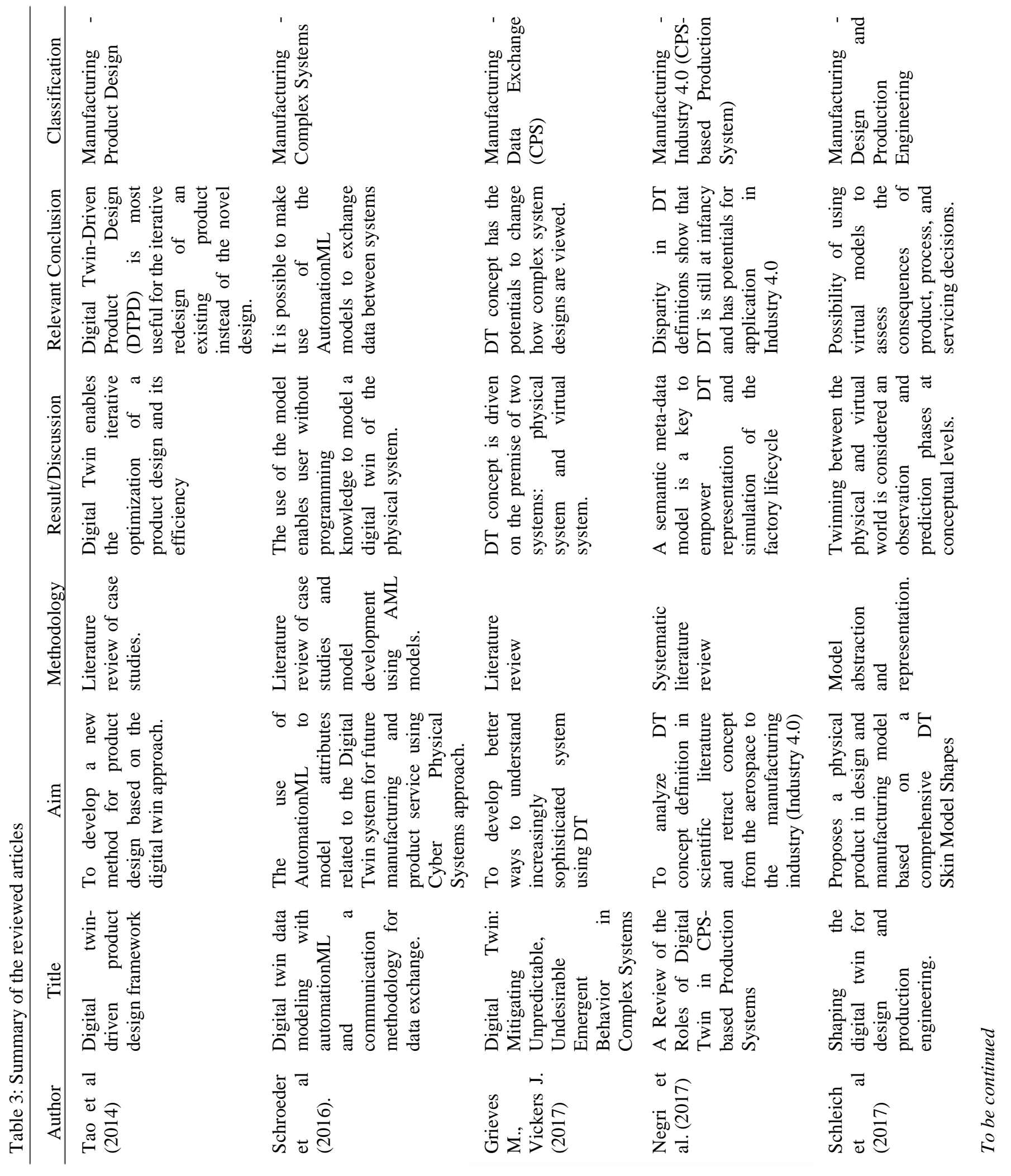




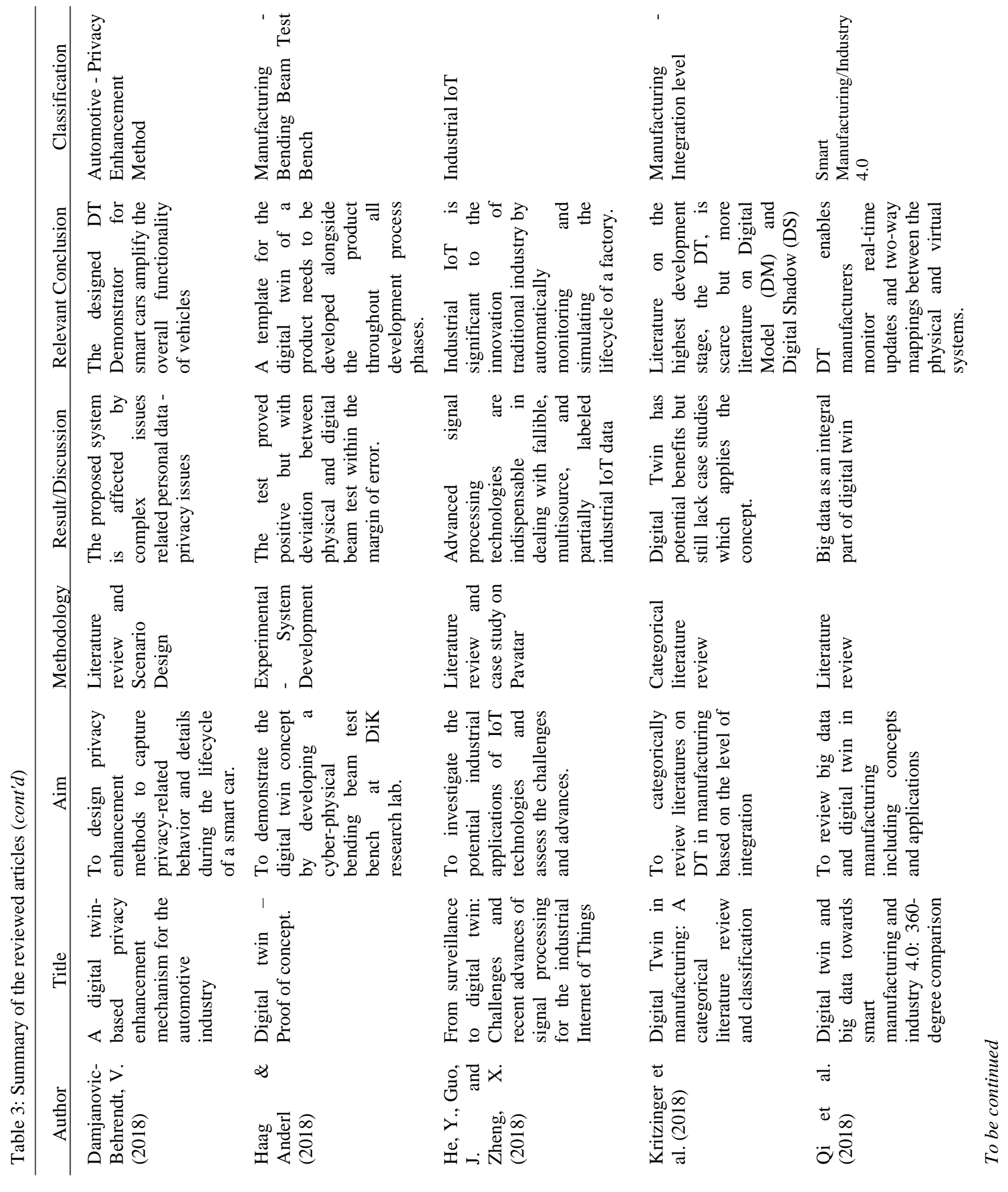




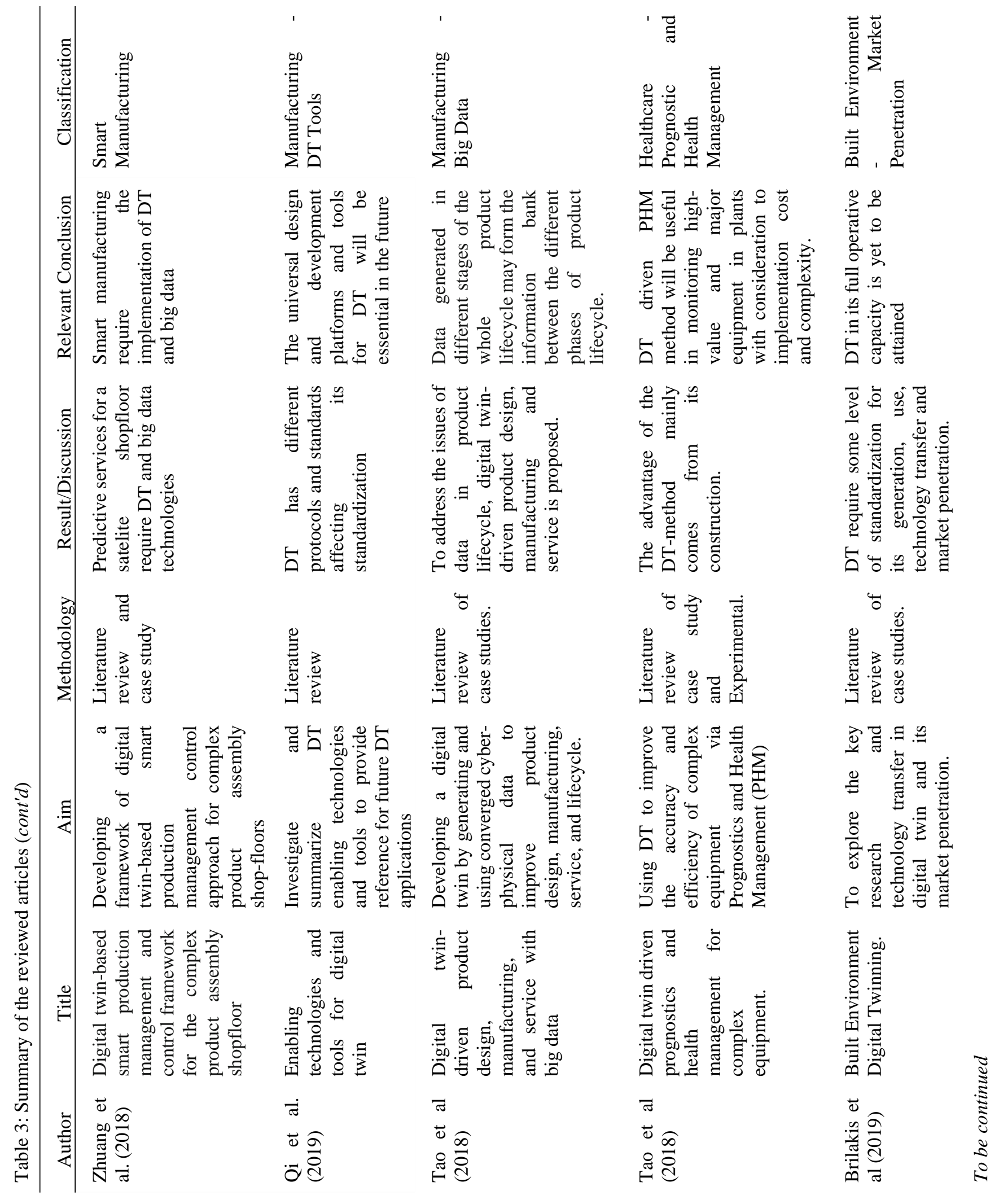




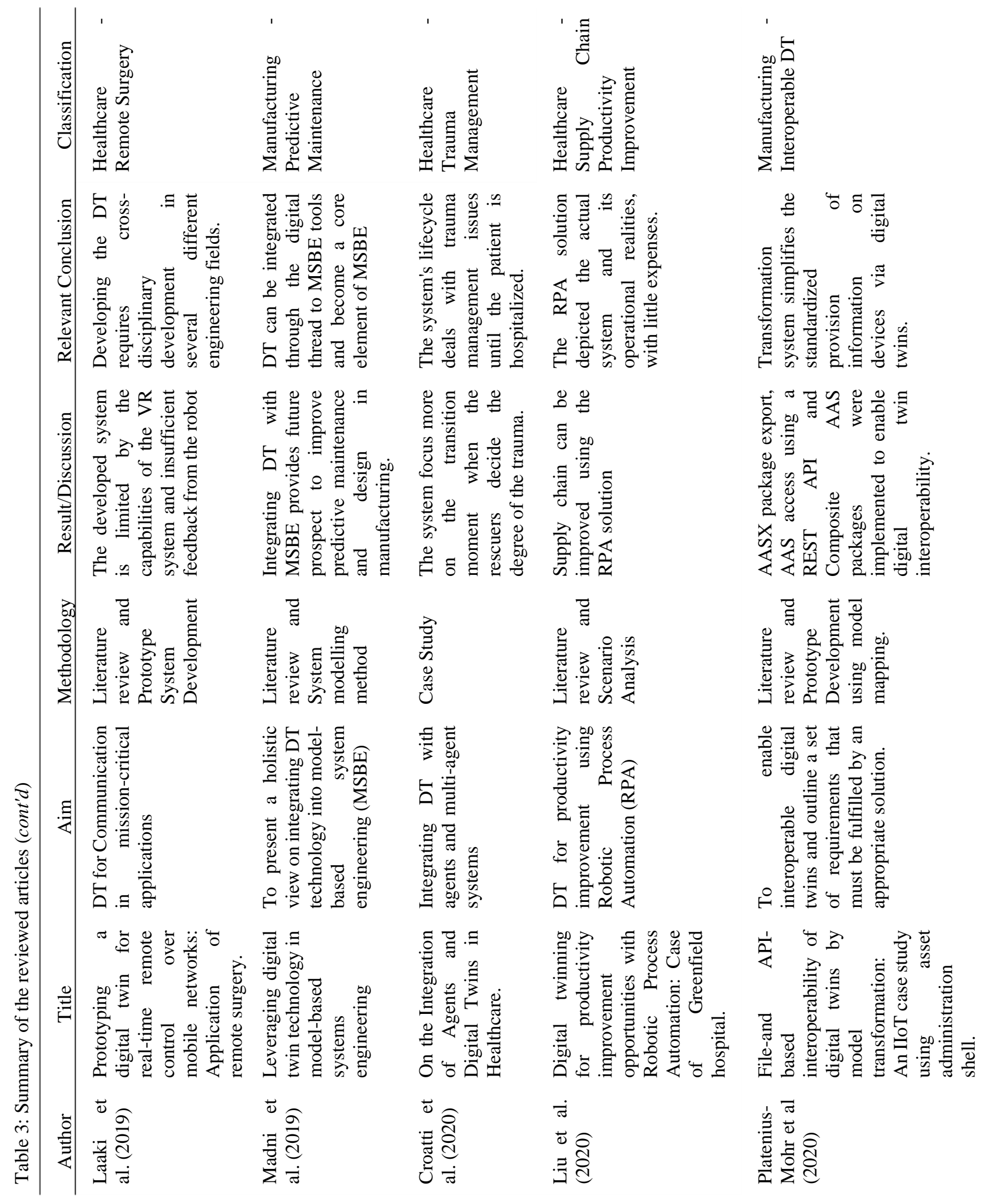




\section{DIGITAL TWIN APPLICATIONS IN OTHER INDUSTRIES}

DT applications have made their way into various industrial sectors and have shown large benefits to them. An example is within the manufacturing industry where DT is yielding powerful and compelling applications leading to improved results (Deloitte, 2017). It provides a virtual replica, which shows what is happening on the factory floor in real-time and aids in the monitoring and control of the processes. This research identified several industries where DT was applied, which are: aerospace, automotive, energy, healthcare, telecommunications, and manufacturing. This section discusses these applications of DT within the various industries and the recorded success. This is used to contrast its application to that in the construction industry and obtain recommendations from the other industries.

\subsection{Aerospace}

The application of DT can be seen at the Structural Sciences Center at the US Air Force Research Laboratory. This application focused on building a realistic high-fidelity flight model which combines both virtual model data with physical data to create an accurate fatigue life prediction (Tao et al, 2017). Before this, Tuegel et al. (2011) identified DT as a system used to predict the reengineering of the structural life of an aircraft. A study by Domone (2018) on aircraft identified that aircraft structures are designed to be weight efficient and as such are required to avoid fatigue failures. To address this, fatigue analysis results, which depend on the molecular level of aircraft geometry, were needed to define the operational lives of aircraft. Currently, it is impossible to cross-examine the molecular structures of an aircraft without first destroying it. There is an ongoing project within the European Union (EU) Clean Sky 2 research program, titled Advanced Landing Gear Sensing \& Monitoring (ALGeSMo) which is being led by Airbus and targeted at providing appropriate sensors for this purpose.

Test-Fuchs is another leading manufacturing company in test systems and components for aerospace and defense organizations that have successfully implemented a dedicated DT approach for ground support assets and test equipment (Aerospace Manufacturing, 2020). DT has also been applied in other areas such as the Department of Defense's (DoD's) Digital Engineering initiative which aims to connect systems and operations using interconnected and smart physical devices (West \& Pyster, 2015). It was also proposed and used in product/equipment prognostics and health management (PHM) (Tao et al, 2018).

A damage characterization method based on DT for aircraft structural health management was proposed by Seshadri and Krishnamurthy (2017) to show significant progress in forecasting the location of damage, size, and orientation. Another application of DT is on Airframe Digital Twin (ADT) used to assess flight state which helps determine damages in real-time (Gockel et al., 2012). DT was successfully implemented by Bielefeldt et al. (2015) to monitor damage in aircraft and was achieved using the wings of the aircraft. Currently, DT is also primarily applied in the field of aeronautics and astronautics to predict failure in the product service and maintenance phase. The implementation of DT in the Aerospace industry is seen with some growth, and this is an encouragement for the construction industry to adopt DT.

\subsection{Automotive Industry}

The automotive industry is one of the many disruptive industries that has various car makes, models, and designs equipped with enhanced functionalities that make driving easy. The designs of cars have moved from basic manual cars to automatic vehicles with automated control systems. Some examples of these automated systems include a lane monitoring system, free-hand driving, and proximity sensors that either raise an alarm or switch off the car once the sensor senses the car is close to an object. Tesla is a good example of a car model with an advanced automation system. Tesla also adopts a DT approach by using technologies such as the Internet of Things (IoT), Artificial Intelligence (AI), Machine Learning (ML), predictive analysis, and simulation tools to model and design their cars (Lahoti, 2021). DT has also been identified as a major key in the long-term success of autonomous vehicles in the future (Watts, 2018). The digital model of a vehicle is first designed and using data from real-life driving scenarios, the model is analyzed through simulations to help engineers determine how the vehicle will perform before design. The vehicle data required for simulation purposes include data on aerodynamics, motor, suspension, body design, and materials (Watts, 2018). This can also be applied in the construction industry using BIM to produce the digital model which would be simulated using the DT approach to analyze the feasibility of the model. 
Tesla is currently implementing a DT approach in the design of their cars, particularly the Model S series which is the new series designed as bespoke and tailored to consumers' demands. The Tesla S series are designed with mobile applications which monitor and control some of the cars' features such as the charging process, the status and temperature control, real-time location of the car, and using the lights/horn to identify the parking location (Capgemini, 2014). Furthermore, the Tesla cars are connected to a remote center which obtains data from the cars to improve safety parameters and add new features (Value Walk, 2014). In 2013, three Tesla Model S series encountered burnouts, and updates were released by the company to improve the vehicles' settings (Capgemini, 2014). Another study by Damjanovic-Behrendt (2018) designed a DT -based privacy enhancement method and a system to capture privacy-related behaviors and anomalies during smart car operational driving lifestyle. This was achieved using Machine Learning (ML) to analyze behavior and forecast smart car operational processes and check for compliance with General Data Protection Regulation (GDPR). Figure 4 shows the process of implementing DT-based privacy enhancement on smart cars.

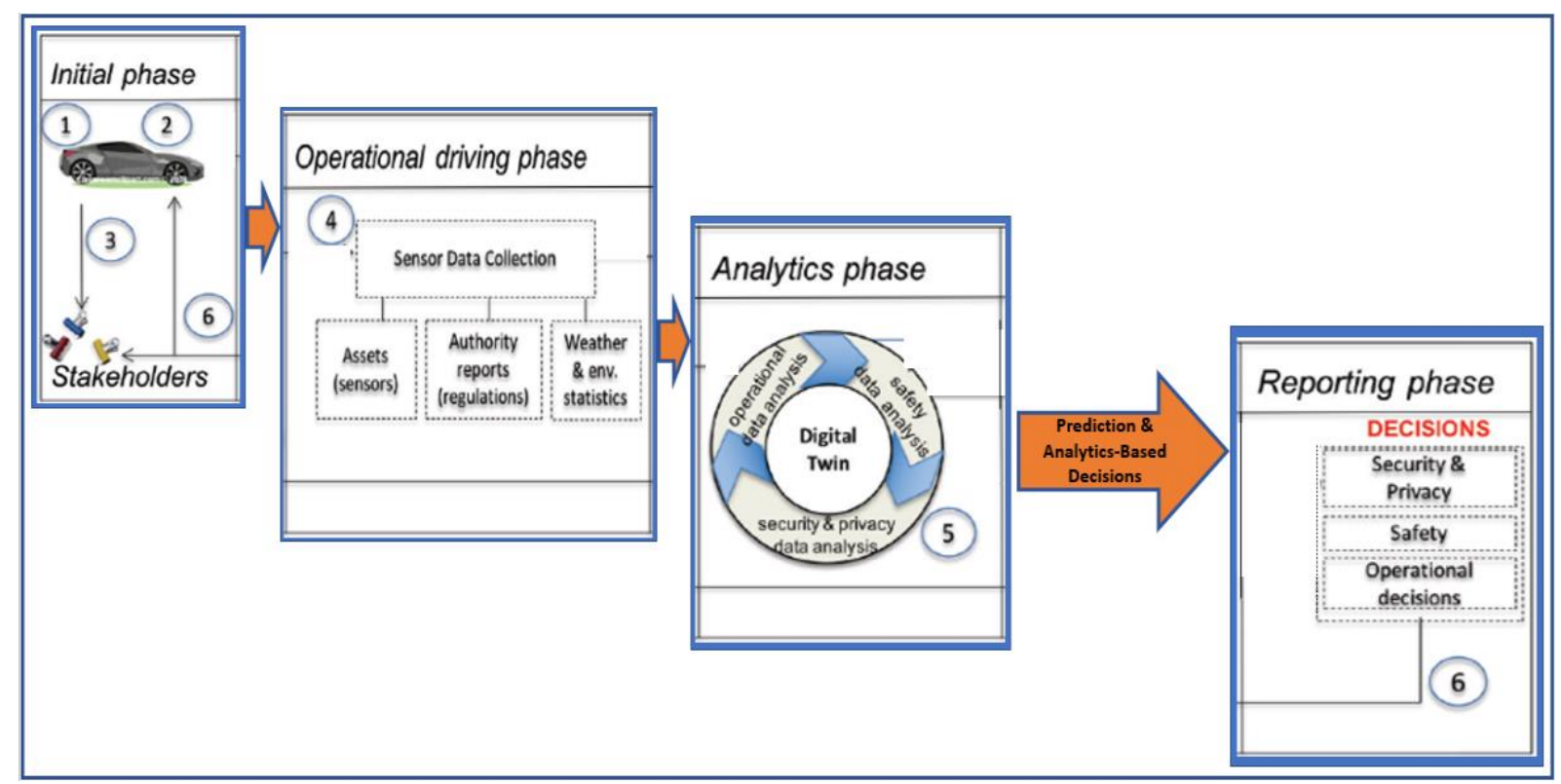

FIG 4: DT smart car scenario (Adapted from Damjanovic-Behrendt, 2018).

Damjanovic-Behrendt (2018) explained the processes implemented in Figure 3 to address DT-based privacy enhancement on smart cars to include:

1. Data of the smart car such as the model of the vehicle, embedded sensors, tire/surface modeling data, and data from the steering wheel.

2. Data on driver's perception such as cues on inertia (orientation), driving skills, and environmental cues (optical and acoustic systems).

3. External systems connectivity data such as manufacturer, importer, retailer, insurance, and third-party networks.

4. Integrating newly collected sensor data with historical data and developing Key Performance Indicators (KPIs) for their analysis and security as well as safety and real-time performance decisions.

5. Using DT to make decisions based on prediction and analyses.

6. Decisions sent to end-users and manufacturers.

\subsection{Energy (Wind Turbines)}

The use of offshore wind turbines to generate electricity is increasing as offshore wind energy is becoming reliable for its energy production (Sivalingam et al., 2018). The Remaining Useful Life (RUL) and maintenance of offshore wind turbines used for energy generation also require effective systems to oversee their performances and RUL. Grid-connected offshore wind power has generated more than $12.631 \mathrm{GW}$ of power in the European Union as of 2016 (European Wind Energy Association, 2016). In addition, Operations and Maintenance (O\&M) of offshore or remotely located turbines have consumed about $25 \%$ of the Levelized Cost of Energy (LCoE) due to accessibility affected by weather conditions such as wind, waves, water levels, or temperature (van Bussel, 2001; 
Sivalingam et al., 2018). Sivalingam et al. (2018) identified that the factors that increased the cost of offshore power generation leading to increased O\&M include failed transfer of technicians onto turbines, abandonment of technicians at the turbines due to unfavorable weather conditions, and failure of technicians to perform maintenance due to seasickness. Due to these shortcomings, condition-based maintenance that adopted the DT approach was preferred to the outdated time-based preventive maintenance.

Condition-Based Maintenance (CBM) focuses on predicting the abnormalities in a system or product. CBM is the most preferable approach as it helps to diagnose equipment's health status and identify possible solutions. This preventive maintenance type integrates with DT to ensure real-time monitoring and management. In Europe, a CBM DT approach is used to obtain information on the condition and performance of the turbines, a networkintegrated Supervisory Control and Data Acquisition (SCADA) platform were employed to obtain information used in creating the DT (Sivalingam et al., 2018). The idea of the CBM study was to implement effective maintenance in the perspective of DT which would reduce the cost of O\&M and in turn LCoE. Condition monitoring in the perspective of DT was employed for prognostics as it made it easy to predict damage accumulation and RUL. Condition-Based Maintenance using a DT approach for facilities management would help improve the performance of constructed projects by monitoring and controlling their health status in real-time.

Currently, General Electric (GE) is developing a software platform called Predix which contains the virtual versions of GE's wind, gas, and steam turbines (GE, 2021). This concept is termed the "digital twin farm" which uses a DT to monitor and improve the functionalities of the turbines (Harvard Business Review, 2015). These turbines are created in the cloud and supplied with the necessary data which helps determine the performance of the physical turbines based on the strength of the wind and temperature of the turbines' motors. Sensors were attached to the turbines which are represented virtually on the digital twin-turbine to obtain temperature information and then an application was developed to monitor and estimate the turbine's temperature (GE, 2021). The GE DT concept has two major key parts: a modular, 2-megawatt wind turbine customized for specific locations and the software that monitors and optimizes performance (Harvard Business Review, 2015). Harvard Business Review (2015) further identified that GE proposes to boost wind farm energy production by $20 \%$ and generate about $\$ 100$ million as extra value over the lifespan of a 100-megawatt farm.

\subsection{Healthcare}

Several DT applications were identified for the healthcare sector. For example, Laaki et al. (2019) developed an application for remote surgery by prototyping a DT for real-time remote control using mobile networks. The developed system is made up of a robotic arm linked to an HTC Vive virtual reality (VR) system using a 4G mobile network. The remote surgery was chosen to test DT applications because the operation requires near-zero latency and high security and reliability levels (Zhang et al., 2018). The DT platform used for remote robotic arm surgery includes Unity 3D and an Open virtual reality system (Laaki et al., 2019). Healthcare is inclining towards remote surgeries, which require bi-directional coordination (DT). The idea to perform remote surgeries did not just surface as a remote surgery (cholecystectomy - surgical removal of gall bladder) was carried out in 2001 over a distance of $6230 \mathrm{~km}$ between the patient and the surgeon (Marescaux et al., 2001). However, the limitation in this design was that connection was strictly set up for a single operation and thus would require separate set-ups for other operations (Laaki et al., 2019). This design would waste time for set-ups and limit appropriate feedback for the surgeon. A study by Croatti et al. (2020) focused on integrating agents and DT for trauma management in healthcare. The focus was to improve the documentation involved in trauma cases and assist the healthcare professionals in carrying out their duties even before the arrival of the trauma patients.

Another DT application in healthcare involved improving healthcare supply chain productivity through Robotic Process Automation (RPA) (Liu et al., 2020). This DT application was developed to improve the logistic system using Greenfield hospital in Singapore as a case study. Anderson and McDaniel Jr. (2000) identified the need to improve efficiency in operations and workflows to treat more patients without cost increase and complexities. The DT solution for the logistics system involved designing an effective supply chain system, developing a strong RPA solution, and reducing the disruption of automation introduction (Bhattacharjee \& Ray, 2014). The Greenfield hospital is a large hospital with 1,800 beds, 8 medical towers of 7 levels each integrated with a common ground floor and two basements (Liu et al., 2020). The key components of the DT framework for this design include the RPA solution development, 3D building information, the hospital's activities schedule, flow simulation and optimization, and scenario analyses (Liu et al., 2020). The platforms used to achieve the DT application were Robotic Process Automation (RPA) and SIMIO ver.9.0. The study by Liu et al. (2020) reported that optimization 
was met in the hospital supply chain system and thus cutting building operational costs, operational uncertainties, and tight budgetary constraints.

\subsection{Telecommunications}

DT has been applied in different industries including telecommunication. Telecommunications, in this respect, refers to the communication networks and signals concerning the Internet of Things (IoT) employed in any technological setting. Advances in IoT have improved the significance of Information Technology (IT) employed in modern industries by upgrading IT from solely providing surveillance-centric functions to building a comprehensive information framework of the industrial process (He et al., 2018). Several connected devices are offering smart services such as building surveillance, assisted living, traffic control, and environmental monitoring (Middleton et al., 2018). However, communication between the smart devices and systems still experienced issues such as delay in network transmission, expensive limited bandwidth, and privacy. Additionally, cloud-based solutions for large-scale videos for industrial purposes are infeasible due to the cost of high-performance cloud servers (He et al., 2017). To address these issues, DT was employed to improve communication between smart connected devices with industrial IoT by employing a Cross-Technology Communication platform was implemented which operates in real-time deep learning directly on end devices. CTC enables heterogeneous devices to exchange information thus meeting the industrial IoT requirements quickly and directly (He et al., 2017). Figure 5 shows the architecture of the CTC platform.

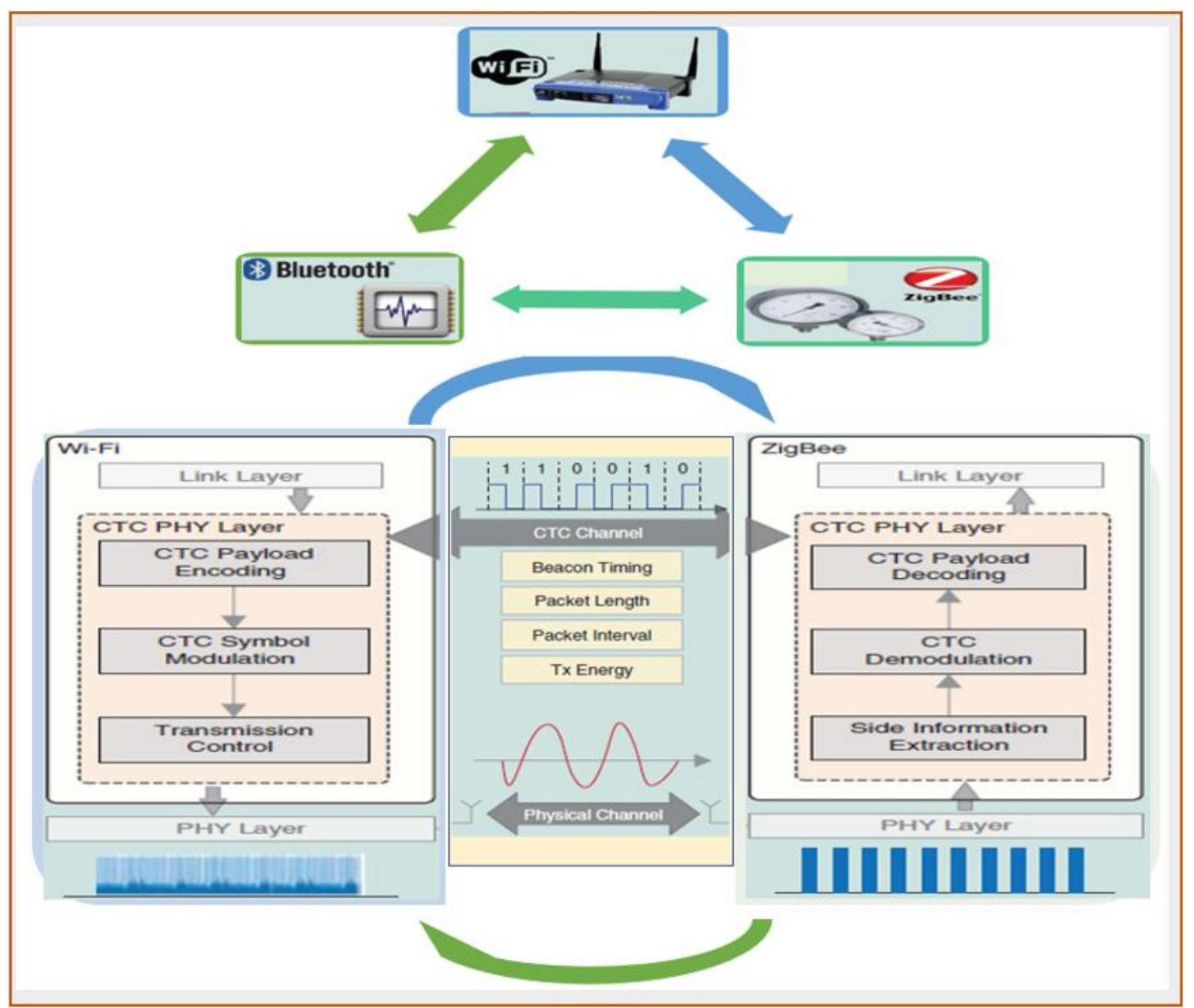

FIG 5: The Architecture of CTC (Adapted from He et al., 2018).

Another DT application in telecommunications is the possibility of medical operations supported by mobile networks (Laaki et al., 2019). One application could be to focus on the communication system that would ensure effective robotic surgery (Laaki et al., 2019). This entails using DT to enable communication between surgery 
robotic hands and systems in real-time and more so, automatically. The study by Laaki et al. (2019) employed both hardware and software integrated with virtual reality to implement robot hand surgery. The Universal Robots UR3, which is a compact collaborative robot, was employed for the robot hand as it met major safety requirements. Furthermore, the study also employed Unity 3D and Open VR which is a Software Development Kit (SDK). Unity 3D was used to create virtual reality while Open VR was used to create the contents of the virtual reality. The hardware and software were set up to create a VR which resembles a medical setting. Subsequently, the communications within the system were developed to complete the DT setup. Figure 6 shows a schematic of the network setup diagram of the prototype system.

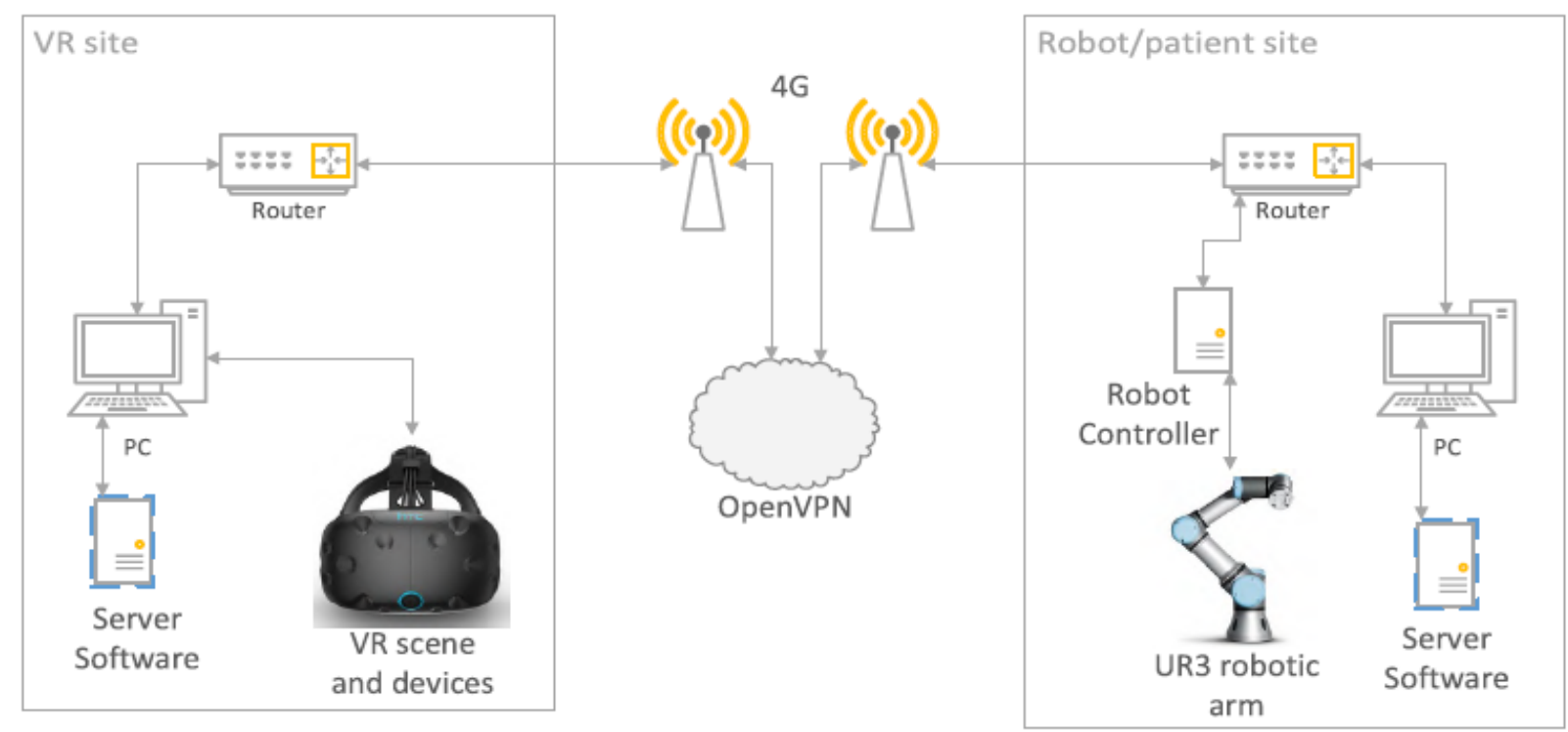

FIG 6: Schematic of the network setup (Source: Laaki et al., 2019).

\subsection{Manufacturing}

With the advent of the internet, the internet of things, big data, cloud computing, and artificial intelligence, the manufacturing industry has been employing smart technologies for production processes. It was predicted that over 20 billion devices (mostly from the manufacturing industry) would be connected to the internet by 2020 (Mourtzis et al, 2016). Consequently, this would lead to the generation of huge amounts of data of over 40 zettabytes (ZB) by 2020 (Gantz \& Reinsel, 2012), including structured, semi-structured, and unstructured data (Qi $\&$ Tao, 2018).

Before the stage of huge data management, the manufacturing industry has undergone various stages seeking improvements. Roy et al. (2020) provided a summary of the various stages of the manufacturing industry from Industry 1.0 to the current Industry 4.0 following the industrial revolution. Industry 1.0 saw the use of the steam engine, which although seemed like an improvement, lacked efficiency, and consumed time. Industry 2.0 brought about the assembly line concept and led to reduced manufacturing lead time. Industry 3.0 embraced computerintegrated manufacturing to replace labor. The current stage, industry 4.0, has integrated digitization which combines the physical world to the virtual world (Digital Twin).

DT provides further advancement on smart manufacturing by managing these data by providing relevant information in real-time. The digitalization of the manufacturing industry has led to more opportunities in smart manufacturing that require an automatic and real-time collection of manufacturing data using IoT (Tao et al, 2014). Tao and Zhang (2017) identified that the scope, degree, functions of the cyber world of manufacturing, and the integration with the physical world have been strengthened by the advent of DT. Figure 7 shows a DT in manufacturing with a close loop and optimization of the product design, manufacturing, and smart maintenance, repair, and overhaul (MRO). 


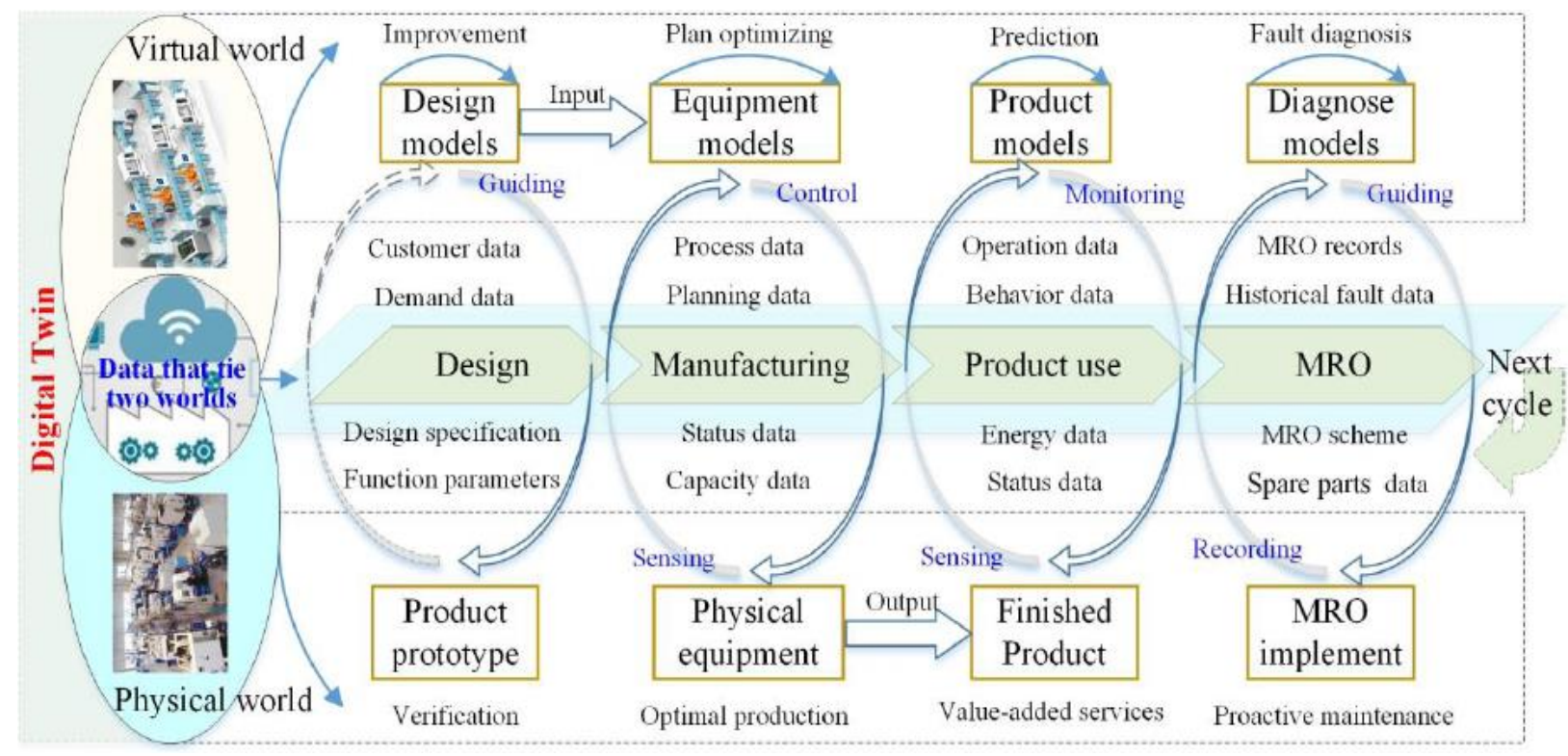

FIG 7: DT in manufacturing (Source: Tao et al, 2017).

Qi and Tao (2018) identified that the digitalization of the manufacturing sector helps to identify bottlenecks in the manufacturing process and proffer effective solutions, thereby making manufacturing leaner and more competitive. Some applications of DT in the manufacturing industry include DT for the manufacturing shop floor (Roy et al., 2020). This concept used DT to improve supply chain efficiency, optimize tasks and energy consumption on the shop floor, improve product assembly, and geometry assurance. The successful implementation of DT is also seen in the field of geometry assurance (Wärmefjord et al., 2017; Söderberg et al., 2017). In this field, the developed DT for geometry assurance is linked to the inspection database and includes the geometry interpretation of the assembly line, kinematic relations, properties of materials, and simulation. DT was applied in the design stage to design exceptional products and improve tolerance. It was also applied at the production stage to monitor and control the products by feeding its virtual model with data on the geometry.

Other DT applications in the manufacturing industry include a multi-objective optimization algorithm DT model with a computational system and a simulation platform to monitor hollow gas pipeline (process monitoring) (Zhang et al., 2017) and a DT monitoring of machines using a Finite Element (FE) model of a Computer Numerical Control (CNC) machine (Scaglioni et al., 2018). There is a variety of DT applications in the manufacturing industry, and they have similarities in purpose. These applications can be categorized under four headings as discussed below (Qi \& Tao, 2018):

\subsubsection{Digital Twin Based Product Design}

Gero and Kannengiesser (2004) identified that the product design phase involves the forward and backward interactions between the expected, interpreted, and physical worlds. This phase entails designing the product as a virtual model based on the designer's expectations and the practical constraints in the physical world (Qi \& Tao, 2018). A DT provides a platform to develop optimized and personalized designs that meet the designers' or consumers' intent before the production phase. In addition, it could save time and cost by identifying defects, verifying, and forecasting product functions, behavior, structures, and manufacturability in the virtual world before production (Tao et al, 2017).

\subsubsection{Smart Manufacturing in Digital Twin Workshop/Factory}

The approved product design is inputted into the smart factory or workshop where the manufacturing of the design from the raw materials to the output product is managed and optimized by DT through the virtual workshop or factory (Rosen et al, 2015). Tao et al. (2017) identified that the virtual workshop or factory contains the geometrical and physical models of the operator(s), materials, environment, equipment, and tools as well as the behaviors, rules, and dynamic models. Before manufacturing, the resources and capabilities are assigned in the virtual world with devised production plans that automate and guide the manufacturing process (Qi \& Tao, 2018). DT enables 
the virtual workshop or factory to evaluate and simulate different manufacturing processes and planning until a viable and satisfactory manufacturing process and a plan is confirmed. The manufacturing process is also monitored and controlled by the virtual model based on real-time data exchange with the physical model being created.

\subsubsection{Product Digital Twin for Usage Monitoring}

DT goes beyond designing a product in a virtual world and automating the manufacturing process. It also provides a platform to virtually monitor and exert some level of control over the physical artifact. Implementing DT at the product design and manufacturing phase enables effective monitoring of the product while in use and thus ensures value-added services during usage (Zhuang et al, 2017). These value-added services include real-time monitoring of the physical systems while updating multi-source product data (such as product usage status data, environment data, and operating parameters), simulating the operational conditions of products in different environments, and using real-time data from physical product and historical data to accurately predict product remaining life, faults, and proffer solutions (Tuegel et al, 2014).

\subsubsection{Digital Twin as an Enabler for Smart Maintenance, Repair, and Overhaul (MRO)}

DT serves as an enabler for smart MRO by ensuring that proactive maintenance for products is carried out to avert downtime due to unforeseen breakdowns (Qi \& Tao, 2018). Proactive maintenance is implemented by monitoring the health condition, remaining life, and faults of the product in real-time. Furthermore, at the instance of fault occurrence, the ultra-high-fidelity virtual models created via DT can diagnose and analyze faults and make these faults known to users and servicemen (Gockel et al, 2012). Currently, General Electric is working on using DT to forecast product health in the product life cycle to enhance the accuracy of its operations and maintenance (Tao et al, 2018). Table 4 provides a summary of the diverse applications of DT within various industries but is not exhaustive of all DT applications mentioned.

Table 4: Applications of DT in various Industry Sectors

\begin{tabular}{ll}
\hline INDUSTRY & USE CASE \\
\hline Aerospace & $\begin{array}{l}\text { An aircraft engine can be viewed in-flight including its temperature and stresses on its parts. The DT } \\
\text { model can be used to identify safety risks and act accordingly. }\end{array}$ \\
Automotive & $\begin{array}{l}\text { Behavioral and operational data of a connected vehicle helps in analyzing the overall vehicle } \\
\text { performance to deliver a truly personalized/customized service for the customers. }\end{array}$ \\
Energy & $\begin{array}{l}\text { An example is the use of DT to improve the efficiency of offshore wind turbines through-Conditioned } \\
\text { Based Maintenance (CBM), increasing efficiency up to 20\% and generating about } \$ 100 \text { million over in } \\
\text { the windfarm's lifespan. }\end{array}$ \\
Healthcare & $\begin{array}{l}\text { Prototyping a DT for real-time remote control over mobile networks: application of remote surgery and } \\
\text { healthcare supply chain system. }\end{array}$ \\
Telecom & $\begin{array}{l}\text { Improving onsite interaction with a product (tower, switches) using Augmented Reality (AR), service } \\
\text { data, simulation analysis and results from big data analytics. }\end{array}$ \\
Manufacturing & $\begin{array}{l}\text { Simulating products using a DT, before actual manufacturing, can help companies eliminate future } \\
\text { processing errors and improve their fabrication throughputs such as for semiconductor production. }\end{array}$ \\
\hline
\end{tabular}

\section{DIGITAL TWIN APPLICATIONS IN THE CONSTRUCTION INDUSTRY}

This section reviews the current state of DT application in the construction industry and its main features, which are real-time updates and bi-directional coordination. Even with the rise of smart buildings embedded with smart automated systems, the adoption of DT in the construction industry has been low compared to the other industries. However, the rise in the construction of smart and intelligent buildings provides a good basis for the adoption of DT. The potential of DT in the construction industry goes beyond buildings with embedded automated systems to the synchronization of the systems such that there is tight coordination between the physical buildings and cyber worlds (Cyber-Physical systems). The introduction of cyber-physical systems into building design and construction offers a path to more sophisticated and intelligent buildings (Anumba et al, 2010; Akanmu et al, 
2011). These buildings are embedded with automated sensors, actuators, and other technologies that serve as a bridge to monitor and control the physical assets. This serves as a basis for DT implementation.

DT operates on the principle of real-time updates and bi-directional coordination (Palit \& Datta, 2017). DT in technology provides a dynamic model, which is better created at the inception stage before the actual product is constructed (Grieves \& Vickers, 2016). However, the creation of DT depends on the sensory data obtained from the physical model. This enables necessary data of the physical assets to be uploaded into the virtual model, which in turn allows for easy control and monitoring of the product. The virtual model created can also be viewed by project managers or analysts on their mobile devices (Palit \& Datta, 2017). Therefore, creating a DT at the nascent stage of a project would ensure tight synchronization and effective performance of the building.

Building operations and life-cycle management can be optimized over time and this depends on the level of accumulated information by DT technology. The accumulated information and data generated by the sensors embedded in the physical systems are responsible for the outcome of the DT. When it comes to the design and the built environment, Keen (2019) identified that DT includes features such as Building Information Modeling (BIM) and 3D models, 2D models, schedules, contracts, construction documents (submittals, change orders, RFIs, etc.), operational data collected by the embedded sensors, and data from AI and machine learning technology. The synchronization of these features enables smart building operators to have access, control, detect faults, and make smart decisions over the various systems, workspaces, and their ensembles within an asset.

The application of DT in the built environment has already been implemented in Singapore's Frasers Tower, which provides a connected workplace for DT purposes (BIM News, 2020). Bentley Systems and Schneider Electric worked on this project where they collected data using a mix of 179 Bluetooth beacons in meeting rooms and 900 sensors for lighting, air quality, and temperature. The platform uses embedded sensors and telemetry to generate about 2,100 data points connected to the cloud using Microsoft Azure to create enabling holistic management of the environment. Even with the case of Singapore, the current adoption of DT solutions in the construction industry is still low when compared to the other industries. A study by Bughin et al. (2016) shows that the adoption rate of digitization in the construction industry is still low at $1.4 \%$ as against the Information and Communications Technology industry, which has the highest digitization adoption rate of $4.6 \%$. However, the study was carried out between the periods of 2005 - 2014, so the digitization adoption in the construction industry may have increased since then. As confirmed by Brilakis et al. (2019), DT is yet to fully gain grounds in the built environment with the potential it has to offer to the associated stakeholders.

When developing a DT, it is essential to define the purpose for which the DT is being developed. The purpose of the DT determines what physical asset to digitize and the Level of Detail (LoD) that is needed for the DT creation (Brilakis et al., 2019). This is because a DT involves complex analytics and is a concept applicable to any field. In the construction industry, DT can be defined to address a particular purpose of the industry or project. Braun et al. (2018), defined the purpose of a DT to be a monitor for construction work progress. Another DT application in the construction industry defined the purpose of the DT for monitoring the state of a bridge (Sacks et al., 2018). Figure 8 shows a geometric digital model of a bridge developed through an automatic process of generating 3D models from point clouds captured by laser scanners (Sacks et al, 2018). A geometric DT is referred to as a geometric digital model enhanced with semantic information and serves as a starting point for creating a comprehensive DT (Brilakis et al., 2019). Creating a geometric digital model is the first step in creating a DT because the digital model will be linked with the physical component on which the DT application will be based.
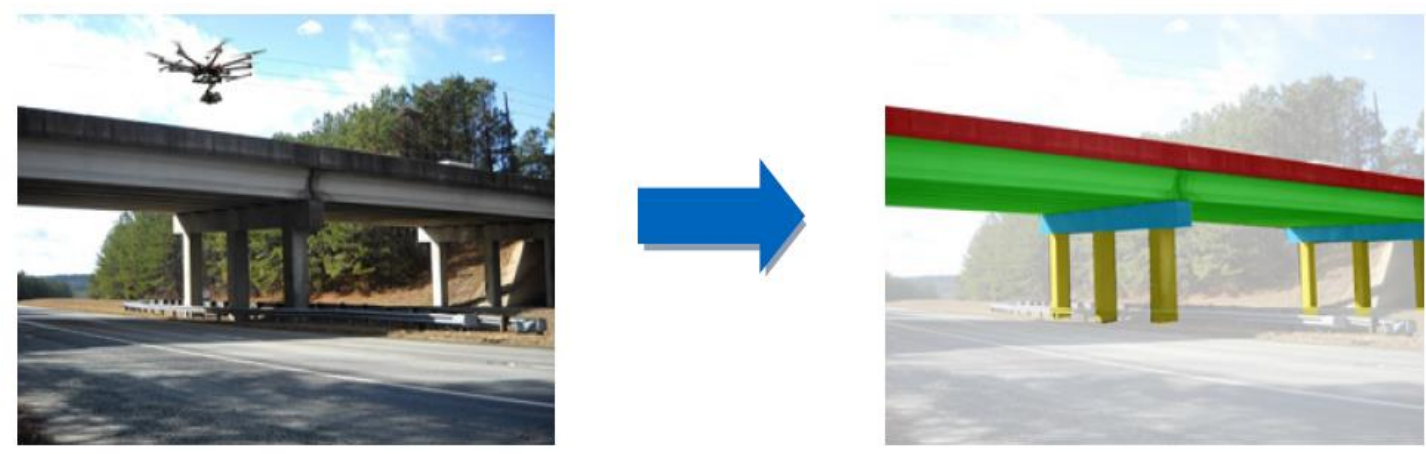

FIG 8: Geometric digital model of a bridge (Source: Sacks et al, 2018). 
The generation of the 3D models needed in creating the digital model can be obtained using Building Information Models (BIM), which is an essential tool in the design, construction, and operation of a facility (Brilakis et al, 2019). BIM provides an important input (including geometrical inputs) for DT, particularly for new projects. Laser scanning or photogrammetry are useful in the automated data acquisition process for geometric DT when dealing with existing structures without digital models (Brilakis et al, 2019). It is observed that although these processes are automated, they are still time-consuming when compared to employing digital models generated using BIM. This was determined by Agapaki et al. (2018) who identified that the man-hours spent in modeling 53,834 pipes were around 5,200 labor hours, which can be employed in other productive areas if the digital models of the facilities are available. However, efforts are being made to automate the modeling process of existing structures with the aid of Artificial Intelligence (AI). Qi et al. (2017) used point cloud semantic segmentation using deep learning to automate the modeling process of office spaces. The output model is like the input model with all geometry except for the final color output.

Brilakis et al. (2019) identified that geometric models are generated based on two categories: bottom-up and topdown approaches. The bottom-up method identifies geometric primitives in terms of lines, planes, and cuboids in a point cloud, then groups and categorizes them into a higher-level geometry, followed by identifying the spatial and functional relationships of the object and finally creating a geometric model. The Top-Down method creates geometric models by identifying that objects in the models are uniquely distinguished through their pose and relation to other objects within the built environment such as building-to-floors-to-rooms. This method relies on the context of the asset and is effective on structures that follow standardized contextual rules such as rectangularstyle buildings and highway overpasses. The above explains the methods for generating geometric models from existing structures without digital models needed to create the required DT platform.

Developing the digital model for the DT is followed by linking it up with the physical system. To attain a realtime update on the status of the bridge, sensors are attached to obtain relevant data which are simulated in the IoT cloud platform to produce the expected real-time updates. The data obtained from the physical asset is simulated in the IoT cloud and this is possible with the aid of Artificial Intelligence (AI) and Machine Learning (ML). DT requires a high level of data analytics conducted in the IoT cloud to ensure real-time updates and bi-directional coordination. The data analytics is based on the developed functional specifications of the DT platform which is defined by the purpose of the proposed DT platform. To continuously update the virtual model based on the state of the physical asset, the sensors continually obtain information about the physical asset which is sent to the IoT platform via the communication network and the data simulation is carried out in the IoT platform, and feedback is implemented back on the physical asset through the sensors.

\subsection{Benefits of Digital Twin in Construction}

DT is at its nascent stage in the construction industry and possesses promising benefits and rewards in its applications. The authors have identified various benefits associated with the implementation of DT technology. One major benefit of DT is observed during a facility's performance and operations based on a cost-benefit analysis that can be applied. Although a DT can require a great upfront investment, it can provide significant investment return in the long-run operation of a system (Madni et al, 2019). DT provides significant benefits, some of which include effective data management, anomaly detection for effective maintenance, and access control and management. A report by Deloitte (2017) identified the following benefits: quality, warranty cost and services, operational costs, record retention and serialization, new product introduction cost and lead-time, and revenue growth opportunities. Another report by Johnson Controls (2019) identified the benefits of applying DT in the built environment to be visibility of the physical asset's operations in the virtual model, prediction of the future state of buildings, possibilities of simulating various conditions to determine 'what-if analysis', documentation, and communication to understand and explain behaviors and connect disparate systems such as backend business application to achieve business outcomes.

Conclusively, the benefits of DT application in construction can be summarized to include: automated progress monitoring, updated as-built drawings/models, resource planning and logistics, safety monitoring, quality assessment, optimization of equipment usage, monitoring and tracking of workers, monitoring of a facility, facilities management and operations, decision making and sustainable development (Brilakis et al, 2019). General Electric's implementation of a DT to boost wind farm energy increased energy production by $20 \%$ and generated about $\$ 100$ million as additional profit over the lifespan of a 100-megawatt farm (Harvard Business Review, 2015). Additionally, the other industries have benefited from DT implementation as studies have shown progress with 
industry 4.0 due to DT implementation. The construction industry has not fully harnessed the potential of DT but is slowly working towards that goal. There is hope for the growth of DT implementation in the construction industry given the current increase in construction of smart buildings and emerging big data. Siemens (2018) identified four key elements (as shown in Figure 9) driving digitization of buildings which could serve as a basis for DT applications.

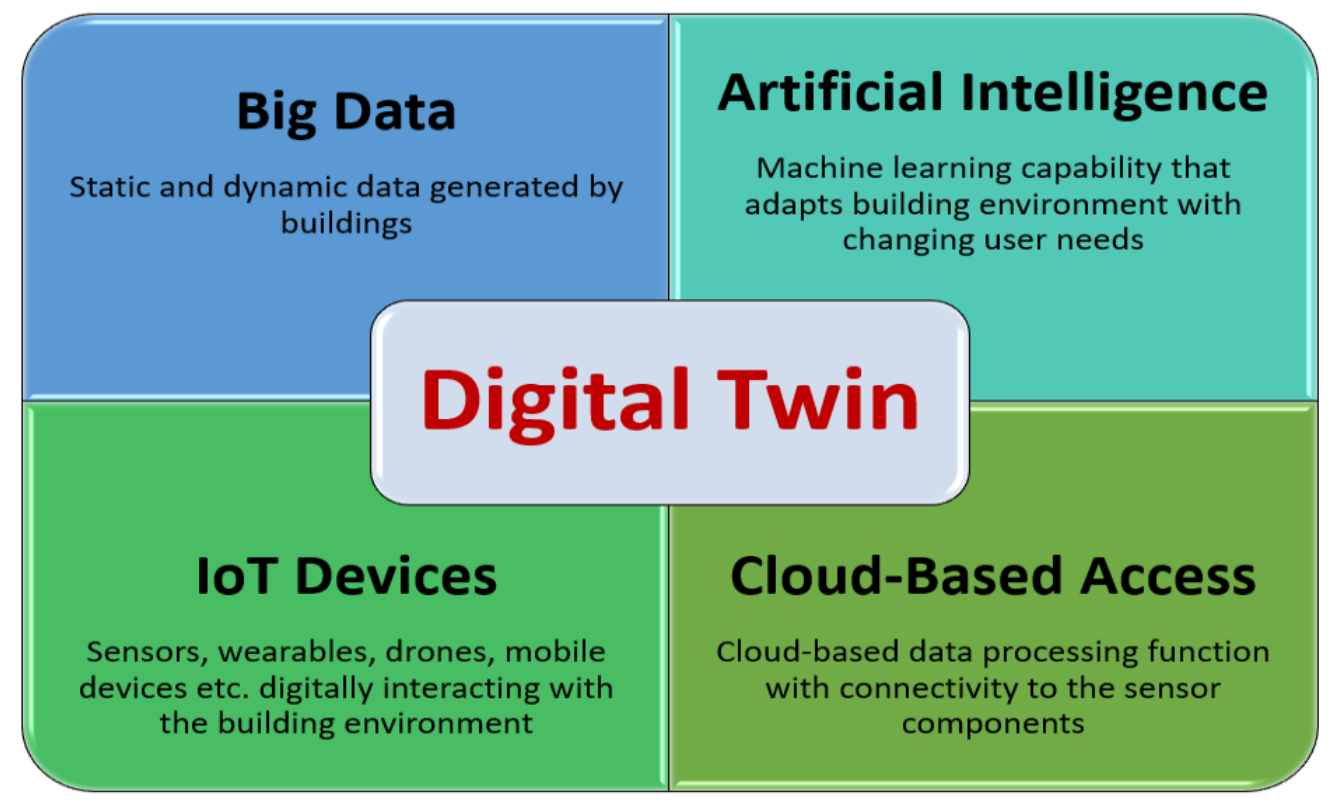

FIG 9: Four key elements driving digitization in building transformation (Adapted from Siemens, 2018).

\subsection{Limitations of Digital Twins in Construction}

The application of DT in other industries has shown considerable progress and benefits within those industries. However, the adoption of DT in construction is still low when compared to the manufacturing industry. Additionally, the process involved in setting up an effective DT requires highly technical and complex steps. The information management system needed to manage the model and data required in setting up a DT involves complex and multifaceted processes (Tune, 2020). Identity Management Institute (2020) identified certain security protocols as challenges to implementing DT, including data encryption, access privileges that include a clear definition of user roles and principle of least privilege, addressing known device vulnerabilities, and routine security audits. These are all applicable to the construction industry and may be compounded by the lower level of technology adoption in the industry. Furthermore, DT requires massive amounts of data to be collected and used that are drawn from numerous endpoints, each representing a potential area of weakness. Lack of interest by the workers for fear of losing their jobs is another limitation that might affect the construction industry. The difficulty in integrating the various stakeholders in the construction industry to work as a single team is another limitation to the adoption of DT in the construction industry (Siemens, 2018).

The slow adoption of digitization in the construction industry can also be attributed to the complex nature of the construction industry. The complexities involved in developing a DT model and the volatile nature of the construction industry make adopting DT in the construction industry a difficult task (Brilakis et al., 2019). This is obvious as no two projects within the construction industry are identical. The lack of a standard in the development of a DT platform in the industry also contributes to this setback in adoption. For example, unlike in construction, the adoption of DT in the design and development of the Tesla Model S cars would require a single standard for all the cars. This is also applicable in manufacturing and other industries, which would require easy replications for all the products manufactured. However, the construction industry would require different DT standards for different construction projects. Considering the complexities involved in developing a DT platform and the complexities of the construction industry, it would be more difficult to convince stakeholders of DT's feasibility especially due to the lower sample size and data that exist on DT implementation in the construction industry. A study by Siemens (2018) revealed that another limitation to the adoption of DT in the construction industry is because "digital" planning and simulation are not included in the budget or the project fee schedules. 


\section{DISCUSSION}

DT is a powerful tool that is making marks in various industry sectors and is gaining attention among both domestic and international scholars and companies. It is defined as the virtual representation of the physical asset and all the instances using real-time information. The virtual models of the physical assets requiring DT are first created and then linked to their physical components using sensors and other smart devices (controllers and actuators), digital platforms, and communication networks. The sensors obtain the required data from the physical components and transfer this information via the networks to the digital platforms. Furthermore, the functionality and effectiveness of DT models depends on the level of information and data about the physical asset accumulated over time. The accumulated data and information obtained require adequate analytics to ensure the automation of the DT concerning the physical system (Buddoo, 2020). The data analytics fully define the feature of real-time update and virtual control of the physical components. Unfortunately, the features of DT are more applied in the other industry sectors than the construction industry.

The Thematic Analysis employed in this study identified various themes on DT publications with regards to various fields and industry sectors. The Thematic Analysis which addresses some of the research questions revealed that more of the publications on DT focused on the manufacturing industry, healthcare sector (service delivery-related), and general DT proof of concept (see Table 3). Further analysis of the themes to identify the mean and percentage value of DT publications with regards to various fields identified that there are DT publications under the category 'construction building technology' with about 8.33 percent (see Table 2). Relating the percentage value to the total number of DT and construction publications shows a total of 24 publications between 2019-2021. However, these publications are more of DT concepts rather than applications as having been applied in the other industries. Consequently, it can be concluded that the extent of DT application in the construction industry is still low given the low volume of publications. Additionally, there is no literature on DT addressing facilities management as a whole or any specific area of facilities management. This is a viable prospect for DT application in the construction industry. Other prospects are identified under DT future works. The Thematic Analysis of the DT publications highlighted by this study provides a holistic view of the extent of DT literature with regards to various fields and industries. However, the themes on DT literature show that DT is applicable in various industries including the construction industry.

The adaptability of DT is responsible for its advancement and applicability in different industries. The manufacturing industry is profiting from the potential benefits of DT such as manufacturing with a closed-loop and optimization of the product design, manufacturing, and smart maintenance, repair, and overhaul (MRO) (Tao et al., 2017). The application of DT in the manufacturing industry is classified under four headings: DT-based product design, smart manufacturing in DT workshop/factory, product DT for usage monitoring, and DT enabler for smart MRO. DT applications in the manufacturing industry ensure that production bottlenecks are identified and corrected, thereby ensuring that manufactured products meet the users' demands with little waste in both resources and time.

In the construction industry, building design and construction have upgraded from the usual traditional design and construction to automated buildings (smart buildings) embedded with many smart devices. These smart devices are embedded to improve the performance of the buildings and ensure comfortability for the users. There have been some attempts to implement DT in construction such as in monitoring construction work progress (Braun et al., 2018) and generating the digital model of a bridge using a geometrical model for DT application (Brilakis et al, 2019). These applications present some potential benefits to further DT applications in construction and properly understand its importance.

DT also provides some potential benefits in the construction industry in terms of analyzing the feasibility of a design before construction. It is an essential tool in the planning and coordination of multi-disciplinary solutions with the early verification and validation of early design choices to optimize building performance (Siemens, 2018). DT potential benefits in the design stage span across the lifecycle of a project/product. Ongoing construction projects can be monitored in real-time and compared to the established design to check standards. DT solutions can also be applied to completed construction projects to monitor building performance and exert virtual (bi-directional coordination) where necessary.

Parris et al (2016) categorized the importance of DT into three areas: early warnings, predictions, and optimization. DT can predict a system's response to safety in cases of critical events and can reveal imminent issues before they 
become critical by comparing actual responses to predicted ones (Madni et al, 2019). This is possible as DT simulates past and present data of a physical object collected over time to predict and possibly warn of any pending or critical events. In addition, possible optimization options to improve performance or take preventive or corrective maintenance methods of physical objects can be provided by DT technologies.

DT can monitor a physical asset's current operational status and performance for scheduling preventive and predictive maintenance activities including calibration and tooling management to be analyzed (Turbide, 2017). It can also be used to manage inventories of repair parts to provide details of the needed parts at the right place and time before maintenance implementation by the service technicians. This could be an application of the just-intime method to reduce inventory during the construction or operation of a facility. Buildings could be designed with intelligent systems (sensors, actuators, controls, and more) which operate on the principle of cyber-physical systems - bi-directional coordination between the building's components and the cyber world (Anumba et al, 2020; Anumba and Roofigari-Esfahan, 2020).

\section{CONCLUSIONS}

This paper presented a review of DT technologies in various industries with a focus on construction. DT was found to have several uses in the design, construction, operation, and maintenance of a facility/asset. Using DT technologies in construction, information on an asset and its components can be collected over time to provide relevant knowledge of an asset and its components. This can be used to monitor and control assets and optimize processes throughout their operational lifecycle. The importance of DT technology in constructed facilities also includes predicting the life cycle performance of a facility and creating economic value by optimizing possible future scenarios. This lifecycle prediction allows the implementation of a Condition-Based Maintenance (CBM) regime - the use of real-time data to prioritize and optimize maintenance resources. Although DT adoption has spread to many sectors including construction, its potential has not been fully realized. This paper provided a useful review for academics and practitioners on the state of DT in various industries, with a focus on the construction sector.

The dynamic nature of DT makes its application flexible in different industries and fields once its purpose is defined. The advent of some smart technologies such as Building Information Modelling (BIM), point cloud segmentation, augmented reality, artificial intelligence, machine learning, data analytics, and sensors make DT implementation in the construction industry more feasible. With the complexities in the construction industry, there is a need to implement DT applications to address prevailing issues in the construction industry. DT can be implemented in the design phase to analyze the feasibility of a design before construction. Once implemented at the design phase, it can help monitor work progress and identify deviations from plans. The operations and maintenance stage of a building also needs DT to monitor the building's performance as well as its systems and equipment. Facilities managers can have access to digital models of their facilities operating in real-time and enabling bi-directional coordination to improve decision-making for the building's optimum performance.

Following the DT implementation in other industries, this paper identified examples where DT has been implemented. This study highlighted the shortcomings of the construction industry concerning DT implementation. It also identified how the other sectors have successfully implemented DT and how the construction industry can learn from them. The construction industry needs to adopt DT technology as it proffers numerous benefits. Several countries have embarked on a DT initiative for the built environment and, while they are laudable, these efforts must be established to address critical problems and deliver tangible value. This will require a partnership between industry, policymakers, technology providers, and academic researchers.

Future work on DT and the construction industry can focus on the development of a DT application to monitor construction work progress, construction workers' performance, and healthcare facilities management. Projections show that hospitals, airports, hotels, and other similar projects will experience growth in the adoption of DT because they employ more smart systems for their performance (Siemens, 2018). Furthermore, the more these buildings are technologically enhanced, the more readily digitalization of the facilities management function can be undertaken with considerable benefits for building owners, operators, and occupants. 


\section{REFERENCES}

Abramovici, M., Göbel, J. C. and Dang, H. B (2016). Semantic data management for the development and continuous reconfiguration of smart products and systems. CIRP Ann; 65(1), 185-188.

Aerospace Manufacturing (2020). It is a twin-win with digital. https://www.aero-mag.com/ifs-mro-digital-twinaerospace-15052020/

Agapaki, E., Miatt, G. and Brilakis, I. (2018). Prioritizing object types for modeling existing industrial facilities. Automation in Construction 96, 211-223.

Akanmu A. and Anumba C. J. (2015). Cyber-Physical Systems Integration of BIM and the Physical Construction, Engineering, Construction, and Architectural Management: Special Issue on Advanced ICT and Smart Systems for Innovative Engineering, Construction and Architectural Management, Vol. 22, No. 5, pp. 516-535.

Akanmu A., Anumba C. J., and Messner, J. (2011). Mechanisms for Bi-directional Coordination between Virtual Design and the Physical Construction, Proceedings of the CIB W78-W102 2011: International Conference, Sophia Antipolis, France, 26-28 ${ }^{\text {th }}$ October.

Akanmu A. A., Anumba C. J., and Messner J. I. (2012). An RTLS-based Approach to Cyber-Physical Systems Integration in Design and Construction, International Journal of Distributed Sensor Networks, Vol. 2012, Article ID 596845, 11 pages, doi:10.1155/2012/596845.

Akanmu A. A., Anumba C. J., and Messner J. I. (2013): 'Scenarios for Cyber-Physical Systems Integration in Construction', Journal of Information Technology in Construction, Vol. 18, pp 240-260 (http://www.itcon.org/2013/12).

Akanmu, A. A., Anumba, C. J., and Ogunseiju, O. O. (2021). Towards next-generation cyber-physical systems and digital twins for construction. Journal of Information Technology in Construction (ITcon), Special issue: 'Next Generation ICT - How distant is ubiquitous computing?', Vol. 26, pg. 505-525, DOI: $10.36680 /$ j.itcon.2021.027

Alhojailan, M. I. (2012). Thematic Analysis: A critical review of its process and evaluation. West East Journal of Social Sciences, 1(1); 39-47

Anderson, R. A. and McDaniel Jr., R. R. (2000). Managing health care organizations: where professionalism meets complexity science. Health Care Management Review, 25(1), 83 - 92.

Anumba C. J., Akanmu A. \& Messner J. (2010). Towards a Cyber-Physical Systems Approach to Construction, Proceedings ASCE Construction Research Congress, Banff, Canada, 8-10 ${ }^{\text {th }}$ May 2010.

Anumba C. J., Akanmu A., Yuan X. \& Kan C. (2020). Cyber-Physical Systems Development for Construction Applications, Frontiers of Engineering Management, DOI: 10.1007/s42524-020-0130-4 (21 pp).

Anumba C. J. and Roofigari-Esfahan N. (Eds) (2020): Cyber-Physical Systems in the Built Environment, Springer Publishers, ISBN 978-3-030-41559-4.

Bielefeldt, B., Hochhalter, J., Hartl, D. (2015). Computationally efficient analysis of SMA sensory particles embedded in complex aerostructures using a substructure approach. ASME 2015 Conference on Smart Materials, Adaptive Structures, and Intelligent Systems V001T02A007-V001T02A007

BIM News (2020, March 13). Digital twin creates the blueprint for future smart buildings. BIM Today. https://www.pbctoday.co.uk/news/bim-news/digital-twin-smart-building/73253/

Bhattacharjee, P. and Ray, P. K. (2014). Patient flow modeling and performance analysis of healthcare delivery processes in hospitals: A review and reflections. Computer and Industrial Engineering, 78, 299 - 312.

Boschert, S., Heinich, C. and Rosen, R. (2017). Next-generation digital twin. Proceedings of TMCE, Las Palmas de Grad Canaria, Spain.

Boyatzis, R.E. (1998). Transforming qualitative information: thematic analysis and code development. Sage Publications.

Braun, A.; Tuttas, S.; Stilla, U.; Borrman, A. (2018). BIM-Based Progress Monitoring. In A. Borrmann, M. König, C. Koch, J. Beetz (Eds.): Building Information Modeling: Springer. 
Brilakis, I., Pan, Y., Borrman, A., Mayer, H. G., Rhein, F., Von, C., Pettinato, E., and Wagner, S. (2019). Built environment digital twinning. Report of the International Workshop on Built Environment Digital Twinning presented by TUM Institute for Advanced Study and Siemens AG.

Buddoo, N. (2020, June 17). Innovative Thinker - Atkins' Nick Tune on Digital Twins. New Civil Engineer. https://www.newcivilengineer.com/innovative-thinking/innovative-thinker-atkins-nick-tune-on-digitaltwins-17-06-2020/

Capgemini (2014). Tesla motors: A Silicon Valley version of the automotive business model. Capgemini Consulting. www.capgemini-consulting.com

Castaldini, F. (2019). How digital twin was central to smart buildings. Facility Executive. https://facilityexecutive.com/2019/02/how-digital-twin-technology-is-central-to-smart-buildings/

Croatti, A., Gabling, M., Montagna, S. and Ricci, A. (2020). On the integration of agents and digital twins in healthcare. Journal of Medical Systems, 44: 161.

Damjanovic-Behrendt, V. (2018). A digital twin-based privacy enhancement mechanism for the automotive industry. 2018 International Conference on Intelligent System, pp. 272-279.

Deloitte (2017). Industry 4.0 and the digital twin - Manufacturing meets its match. A Deloitte series on Industry 4.0, Deloitte University Press.

Domone, J. (2018). Digital twin for life predictions in civil aerospace. Atkins White Paper. www.atkinsglobal.com/aerospace

Economic Times CIO (2020, September 25). Digital trends in the facilities management industry. Economic Times CIO. https://cio.economictimes.indiatimes.com/news/next-gen-technologies/digital-trends-in-thefacilities-management-industry/78247538.

European Wind Energy Association (2016, September 2). EWEA 2016 wind report. Available online: https://www.ewea.org/.

Gantz, J. and Reinsel, D (2012). The digital universe in 2020: Big data, bigger digital shadows, and biggest growth in the far East. IDC iView: IDC Analyze Future, 1-16.

GAVS Technologies (2017). Digital Twin concept. (ND).

General Electric (2021, May 12). Building a digital twin, bolstering the power of a wind turbine. Available online: https://www.ge.com/renewableenergy/stories/improving-wind-power-with-digital-twin-turbines

Gero, J. S. and Kannengiesser, U. (2004). The situated function-behavior structure framework. Des. Stud., 25(4), 373_391.

Glaessgen, E. H. and Stargel, D. (2012). The Digital Twin Paradigm for Future NASA and US Air Force Vehicles. 53rd Structural Dynamics Material Conference - Special Session: Digital Twin, Honolulu, HI, US 1-14.

Gockel, B. T., Tudor, A. W., Brandyberry, M. D., Penmetsa, R. C. and Tuegel, E. J. (2012). Challenges with Structural Life Forecasting Using Realistic Mission Profiles. 53rd AIAA/ASME/ASCE/AHS/ASC Structures, Structural Dynamics, and Materials Conference 20th AIAA/ASME/AHS Adaptive Structures Conference 14th AIAA.

Grieves, M. (2005). Product Lifecycle Management: the new paradigm for enterprises. International Journal of Product Development. 2(1/2), 71-84.

Grieves, M. (2014). Digital twin: Manufacturing excellence through virtual factory replication," White paper, [Online].

Available: http://www.apriso.com/library/Whitepaper_Dr_Grieves_DigitalTwin_Manufacturing Excellence.php

Grieves M., Vickers J. (2017). Digital Twin: Mitigating Unpredictable, Undesirable Emergent Behavior in Complex Systems. In: Kahlen F. J., Flumerfelt S., Alves A. (eds) Transdisciplinary Perspectives on Complex Systems. Springer, Cham. https://doi.org/10.1007/978-3-319-38756-7_4

Haag, S. and Anderl, R. (2018). Digital twin - proof of concept. Journal of Manufacturing Letters, 15, 64-66. 
Harvard Business Review (2015, July). How the digital wind farm will make wind power $20 \%$ more efficient. Harvard Business Publishing. https://hbr.org/sponsored/2015/07/how-the-digital-wind-farm-will-makewind-power-20-more-efficient.

He, Y., Guo, J. and Zheng, X. (2018). From surveillance to digital twin: Challenges and recent advances of signal processing for the industrial Internet of Things. IEEE Signal Processing Magazine. DOI: 10.1109/MSP.2018.2842228

Identity Management Institute (2020). Digital twin technology benefits and challenges. https://www.identitymanagementinstitute.org/digital-twin-technology-benefits-and-challenges/

Johnson Controls (2019). Applying digital twin to the built environment. Johnson Control; whitepaper.

Keen, M. (2019). Construction technology defined. What is Digital Twin? Autodesk Construction Cloud. https://constructionblog.autodesk.com/digital-twin/

Kritzinger, W., Karner, M., Tara, G., Henjes, J. and Sihn, W. (2018). Digital Twin in manufacturing: A categorical literature review and classification. IFAC PapersOnline 51-11, 1016-1022.

Laaki, H., Miche, Y. and Tammi, K. (2019). Prototyping a digital twin for real-time remote control over mobile networks: Application of remote surgery. IEEE, 7, 20325-20336. Digital Object Identifier 10.1109/ACCESS.2019.2897018

Lahoti, N. (2021, May 7). How is digital twin technology impacting the automotive industry? Available online: https://mobisoftinfotech.com/resources/blog/digital-twin-technology-impacting-automotive-industry/

Liu, W., Zhang, W., Dutta, B., Wu, Z. and Goh, M. (2020). Digital twinning for productivity improvement opportunities with Robotic Process Automation: Case of Greenfield hospital. International Journal of Mechanical Engineering and Robotics Research 9(2).

Lui, Z., Meyendorf, N. and Mrad, N. (2018). The role of data fusion in predictive maintenance using digital twin. 44th Annual Review of Progress in Quantitative Nondestructive Evaluation, Volume 37. AIP Conference Proceedings. https://doi.org/10.1063/1.5031520

Madni, A. M., Madni, C. C. and Lucero, S. (2019). Leveraging digital twin technology in model-based systems engineering. Systems, 7, 7.

Marescaux, J., Leroy, J., Gagger, M., Rubino, F., Mutter, D., Vix, M., Butner, S. E., Smith, M. K. (2001). Transatlantic robot-assisted telesurgery. Nature; 413(6854), 379-380. DOI: 10.1038/35096636. Erratum in: Nature 2001 Dec 13; 414(6865): 710. PMID: 11574874

Martinez, V., Ouyang, A., N., Neely, A., Burstall, C., and Bisessar, D. (2018). Service business model innovations: The digital twin technology. Working Paper; Cambridge Service Alliance, University of Cambridge,

Middleton, P., Tsai, T., Yamaji, M., Gupta, A., and Ruebe, D. (2017). Forecast: Internet of things - Endpoints and associated services. [Online]. Available: https://www.gartner.com/doc/3840665/forecast-internetthings-endpoints.

Mohammadpour, A., Anumba, C., Bulbul, T., and Messner, J. (2012). Facilities Management Interaction with Healthcare Delivery Process. Construction Research Congress, ASCE, 728-736.

Mourtzis, D., Vlachou, E. and Milas, N. (2016). Industrial big data as a result of IoT adoption in manufacturing. Procedia CIRP, 55, 290-295.

Negri, E., Fumagalli, L. and Macchi, M. (2017). A Review of the Roles of Digital Twin in CPS-based Production Systems. In Procedia Manufacturing, 11, 939-948.

Negroponte, P. N. (1995). Being Digital. Vintage Books, Random House Incorporated. New York, NY.

O’Connor, C. (2019, January 28). IBM IoT Platform. Available online: https://www.ibm.com/blogs/internet-ofthings/leaderiot-platforms/

Oracle Fusion Applications (2017). Digital twins for IoT applications: A comprehensive approach to implementing IoT digital twins. Oracle White Paper. www.oracle.com

Palit, S. and Datta, A. (2017). Emergence of Digital Twins. Journal of Innovation Management, 5, 14-34. 
Parris, C. J., Laflen, J. B., Grabb, M. L. and Kalitan, D. M. (2016). The future for industrial services: The digital twin. External Document; Infosys Limited.

Qi, Q. and Tao, F. (2018). Digital twin and big data towards smart manufacturing and industry 4.0: 360-degree comparison. IEEE, 6, 2169-3536

Qi, Q., Tao, F., Hub, T., Answer, N., Liud, A., Wei, Y., Wang, L., and Nee, A.Y. C. (2019). Enabling technologies and tools for digital twin. Journal of Manufacturing Systems, https://doi.org/10.1016/j.jmsy.2019.10.001

Rosen, R., von Wichert, G., Lo, G. and Bettenhausen, K. D (2015). About the importance of autonomy and digital twins for the future of manufacturing. IFAC Papers OnLine; 48(3), 567-572.

Roy, R. B., Mishra, D., Pal, S. K., Chakravarty, T., Panda, S., Chandra, M. G., Pal, A., Mishra, P., Chakravarty, D., and Mishra, S. (2020). Digital twin: current scenario and a case study on a manufacturing process. The International Journal of Advanced Manufacturing Technology, 107, 3691-3714. https://doi.org/10.1007/s00170-020-05306-w

Sacks, R., Kedar, A., Borrmann, A., Ma, L., Brilakis, I., Hüthwohl, P. and Barutcu, B. E. (2018). See Bridge as next-generation bridge inspection: overview, information delivery manual, and model view definition. Automation in Construction, 90, 134 - 145.

Scaglioni, B., Ferretti, G. (2018). Towards digital twins through object-oriented modeling: a machine tool case study. IFAC-PapersOnLine 51, 613-618. https://doi.org/10.1016/j.ifacol.2018.03.104

Schleich, B., Anwer, N., Mathieu, L. and Wartzack, S. (2017). Shaping the digital twin for design and production engineering. CIRP Annals - Manufacturing Technology 66, 141-144.

Schroeder, G. N., Steinmetz, C., Pereira, C. E. and Espindola, D. B. (2016). Digital Twin Data Modeling with AutomationML and a Communication Methodology for Data Exchange. IFAC-PapersOnLine 49-30, 1217.

Seshadri B. R. and Krishnamurthy T. (2017). Structural Health Management of Damaged Aircraft Structures Using the Digital Twin Concept. DOI: 10.2514/6.2017-1675.

Shafto, M., Conroy, M., and Doyle, R. (2010). NASA Modeling, Simulation, Information Technology \& Processing - TA11.

Siemens (2018). Digital Twin - Driving business value throughout the building life cycle. Whitepaper. www.siemens.com/BIM

Sivalingam, K., Spring, M., Sepulveda, M. and Davies, P. (2018). A Review and methodology development for remaining useful life prediction of offshore fixed and floating wind turbine power converter with digital twin technology perspective. $2^{\text {nd }}$ International Conference on Green Energy and Application, pp. 197204.

Söderberg R, Wärmefjord K, Carlson JS, Lindkvist L (2017). Toward a digital twin for real-time geometry assurance in individualized production. CIRP Ann - Manuf Technol 66, 137-140. https://doi.org/10.1016/j.cirp.2017.04.038

Tao, F., Cheng, J., Cheng, Y., Gu, S., Zheng, T. and Yang, H. (2017). SDM-Sim: A manufacturing service supplydemand matching simulator under cloud environment. Robotic Computer Integrated Manufacturing, 45, 34-46.

Tao, F., Cheng, J., Qi, Q., Zhang, M., Zhang, H., and Sui, F. (2017). Digital twin-driven product design, manufacturing, and service with big data. International Journal of Advanced Manufacturing Technology, DOI: $10.1007 / \mathrm{s} 00170-017-0233-1$

Tao, F., Sui, F., Liu, A., Qi, Q., Zhang, M., Song, B., Guo, Z., Lu, S. C. Y., and Nee, A. Y. C. (2018). Digital twindriven product design framework. International Journal of Production Research, 57(12), 3935-3953.

Tao, F., Zuo, Y., Xu, L. and Zhang, L. (2014). IoT-based intelligent perception and access of manufacturing resources toward cloud manufacturing. IEEE Trans. Ind. Inf., 10(2), 1547_1557.

Tuegel, E. J., Ingraffea, A. R. Eason, T. G. and Spottswood, S. M. (2011). Reengineering Aircraft Structural Life Prediction Using a Digital Twin. International Journal of Aerospace Engineering 154798, 1-14. 
Turbide, D. (2017). The importance of digital twin. Dassault Systems, North America.

Value Walk (2014, August). Tesla vs. Jaguar: It's About Analytics. Available online: https://www.valuewalk.com/2014/08/tesla-vs-jaguar-its-about-analytics/

van Bussel, G. J. W., Henderson, A. R., Morgan, C. A., Smith, S., Barthelmie, R., Argyriadis, K., Arena, A., Niklasson, G. and Peltola, E. (2001). State of the Art and Technology Trends for Offshore Wind Energy: Operation and maintenance issues. In Offshore Wind Energy Special Topic.

Wärmefjord, K., Söderberg, R., Lindkvist, L. et al (2017) Shaping the digital twin for design and production engineering. In: Volume 2: advanced manufacturing. ASME, p V002T02A101

Wärmefjord, K., Söderberg, R., Lindkvist, L. et al (2017) Inspection data to support a digital twin for geometry assurance. In: Volume 2: Advanced Manufacturing. ASME, p V002T02A101

Watt, B. (2018). Digital twins in the automotive industry. Available online: https://www.challenge.org/knowledgeitems/digital-twins-in-the-automotive-industry/

West, T. D., Pyster, A. (2015). Untangling the Digital Thread: The Challenge and Promise of Model-Based Engineering in Defense Acquisition. Insight 18, 45-55.

Zhang, H., Liu, Q., Chen, X. (2017). A digital twin-based approach for designing and decoupling of a hollow glass production line. IEEE Access 1-1. https://doi.org/10.1109/ACCESS.2017.2766453

Zhuang, C., Liu, J. and Xiong, H. (2018). Digital twin-based smart production management and control framework for the complex product assembly shopfloor. The International Journal of Advanced Manufacturing Technology 96,1149-1163. https://doi.org/10.1007/s00170-018-1617-6

Zhang, Q., Liu, J. and Zhao, G. (2018). Towards 5G enabled tactile robotic telesurgery. [Online]. Available: https://arxiv.org/abs/1803.03586

Zhuang, C., Liu, J., Xiong, H., Ding, X., Liu, S. and Wang, G. (2017). Connotation, architecture, and trends of product digital twin. Computer Integrated Manufacturing Systems, 23(4), 753-768. 